\title{
The Neural Cell Adhesion Molecule Promotes FGFR-Dependent Phosphorylation and Membrane Targeting of the Exocyst Complex to Induce Exocytosis in Growth Cones
}

\author{
Yana Chernyshova, ${ }^{1}$ Iryna Leshchyns'ka, ${ }^{1,3}$ Shu-Chan Hsu, ${ }^{2}$ Melitta Schachner, ${ }^{1,2}$ and Vladimir Sytnyk ${ }^{1,3}$ \\ ${ }^{1}$ Zentrum für Molekulare Neurobiologie, Universitätsklinikum Hamburg-Eppendorf, 20246 Hamburg, Germany, ${ }^{2}$ Department of Cell Biology and \\ Neuroscience and Keck Center for Collaborative Neuroscience, Rutgers University, Piscataway, New Jersey 08854-8082, and ${ }^{3}$ School of Biotechnology and \\ Biomolecular Sciences, The University of New South Wales, Sydney, New South Wales 2052, Australia
}

The exocyst complex is an essential regulator of polarized exocytosis involved in morphogenesis of neurons. We show that this complex binds to the intracellular domain of the neural cell adhesion molecule (NCAM). NCAM promotes FGF receptor-mediated phosphorylation of two tyrosine residues in the sec 8 subunit of the exocyst complex and is required for efficient recruitment of the exocyst complex to growth cones. NCAM at the surface of growth cones induces $\mathrm{Ca}^{2+}$-dependent vesicle exocytosis, which is blocked by an inhibitor of L-type voltage-dependent $\mathrm{Ca}^{2+}$ channels and tetanus toxin. Preferential exocytosis in growth cones underlying neurite outgrowth is inhibited in NCAM-deficient neurons as well as in neurons transfected with phosphorylation-deficient sec8 and dominant-negative peptides derived from the intracellular domain of NCAM. Thus, we reveal a novel role for a cell adhesion molecule in that it regulates addition of the new membrane to the cell surface of growth cones in developing neurons.

\section{Introduction}

In the brain, neurons are organized in complex and precise networks, the proper formation of which is indispensable for brain function. Hence, regulation of neurite outgrowth in neurons during ontogenetic development is an important task. Neurite outgrowth requires continuous supply of new plasma membrane to growth cones, which is delivered to the cell surface via intracellular organelles (Shea and Sapirstein, 1988; Zakharenko and Popov, 1998). Mechanisms that coordinate the delivery of new membrane to the cell surface to sustain neurite outgrowth have remained largely unknown.

Neurite outgrowth depends on the concomitant activity of various intracellular signaling cascades activated by adhesion molecules at the cell surface and in the extracellular matrix that affect cytoskeleton remodeling and gene expression (Walmod et al., 2004; Maness and Schachner, 2007). Among them, the neural cell adhesion molecule (NCAM) plays an important role in cell adhesion, cell migration, neural differentiation, synapse formation, and synaptic plasticity (Kiryushko et al., 2004; Sytnyk et al.,

\footnotetext{
Received June 17, 2010; revised Dec. 16, 2010; accepted Dec. 27, 2010.

This work was supported by Deutsche Forschungsgemeinschaft (M.S., I.L., V.S.). We are grateful to Achim Dahlmann for genotyping, Eva Kronberg for maintenance of animals, Peggy Putthoff for assistance with cloning, and Ute Eicke Kohlmorgen for assistance with Western blot and protein purification. We thank Dr. Harold Cremer for NCAM - / - mice, Dr. Roger Tsien, Dr. Gero Miesenböck, and Dr. Moira O'Bryan for the cherry, synaptobrevinpHluorin, and DN-FGFR1 constructs.

Correspondence should be addressed to Vladimir Sytnyk, School of Biotechnology and Biomolecular Sciences, The University of New South Wales, Sydney, NSW 2052, Australia. E-mail: v.sytnyk@unsw.edu.au.

DOI:10.1523/JNEUROSCI.3109-10.2011

Copyright $\odot 2011$ the authors $\quad 0270-6474 / 11 / 313522-14 \$ 15.00 / 0$
}

2004; Maness and Schachner, 2007). NCAM is encoded by a single gene, which gives rise to multiple isoforms generated by alternative splicing generating three major isoforms with the molecular weights of $120 \mathrm{kDa}$ (NCAM120), $140 \mathrm{kDa}$ (NCAM140), and $180 \mathrm{kDa}$ (NCAM180) (Cunningham et al., 1987). In growing neurites, NCAM accumulates in growth cones (Leshchyns'ka et al., 2003; Bodrikov et al., 2005; Santuccione et al., 2005). Binding of NCAM at the neuronal cell surface to its homophilic and heterophilic ligands promotes neuritogenesis (Walsh and Doherty, 1997; Maness and Schachner, 2007).

We have previously shown that NCAM associates with transGolgi network (TGN)-derived organelles by binding to the spectrin cytoskeleton lining membranes of these organelles (Sytnyk et al., 2002), suggesting relationships between NCAM and the membrane biosynthetic pathway. A major role in the addition of plasma membranes to the cell surface at spatially defined membrane domains in neurons and non-neuronal cells is played by the exocyst complex. This $734 \mathrm{kDa}$ complex is comprised of eight subunits: sec3, sec5, sec6, sec8, sec10, sec15, exo84, and exo70 (Matern et al., 2001). Perturbation of exocyst complex function via deletion, mutation, or dominant-negative construct overexpression has been found to inhibit exocytosis in all cell types studied so far (Hsu et al., 2004). In particular, knockdown of the exocyst subunit sec5 and overexpression of dominant-negative sec 8 and sec10 constructs inhibit neurite outgrowth in neurons and neuroendocrine PC12 cells (Vega and Hsu, 2001; Murthy et al., 2003). However, despite its importance in exocytosis, mechanisms underlying the exocyst's role in exocytosis are still largely unknown. 
In the present study, we show that the exo 70 and sec 8 subunits of the exocyst complex directly associate with the intracellular domain of NCAM140. NCAM deficiency results in decreased tyrosine phosphorylation and impaired targeting of the exocyst complex to growth cone membranes. Compartmentalized exocytosis and neurite outgrowth are inhibited in NCAM-deficient neurons and wild-type neurons transfected with phosphorylation-deficient sec8 and dominant-negative NCAM peptides. Hence, our observations indicate a direct exocyst-dependent link between NCAM at the cell surface and the delivery of new surface plasma membrane in NCAM-induced neurite outgrowth.

\section{Materials and Methods}

Antibodies and toxins. Rabbit polyclonal antibodies against mouse NCAM (Niethammer et al, 2002) (for biochemical and immunocytochemical experiments, ELISA, and clustering of mouse NCAM in growth cones), chicken polyclonal antibodies against NCAM (Dr. Pineda, Antibody Service, Berlin, Germany; for clustering of mouse NCAM in growth cones for membrane expansion assays), and rat monoclonal antibodies H28 against mouse NCAM (Gennarini et al., 1984) (for Western blot analysis) react with the extracellular domain of all NCAM isoforms. Mouse monoclonal antibodies against the intracellular domains of NCAM140 and NCAM180 (clone 5b8, Developmental Studies Hybridoma Bank) were used for ELISA. Rabbit polyclonal antibodies against mouse L1 (Rolf et al., 2003) and mouse monoclonal antibodies against exo70 and sec8 (Vega and Hsu, 2001) were as described previously. Rabbit polyclonal antibodies against actin were from Sigma; mouse monoclonal antibodies against $\gamma$-adaptin, clathrin, EEA1, and GM130 were from BD Biosciences; rat monoclonal antibodies against glyceraldehyde3-phosphate dehydrogenase (GAPDH) were from Millipore Bioscience Research Reagents; rat monoclonal antibodies against Lamp1 were from Developmental Studies Hybridoma Bank; mouse monoclonal antibodies against phosphotyrosine (clone PY20) were from Santa Cruz Biotechnology. Secondary antibodies against rabbit, rat, and mouse Ig coupled to HRP, Cy2, Cy3, or Cy5 and nonspecific rabbit, rat, and mouse immunoglobulins (IgG) were from Jackson ImmunoResearch Laboratories. Cholera toxin B subunit coupled to HRP to label GM1 was from Invitrogen, and nifedipine and pimozide were from Alomone Labs.

Animals. NCAM-/- mice were provided by Harold Cremer [The Developmental Biology Institute of Marseilles (IBDML), Marseille, France] (Cremer et al., 1994) and were inbred for at least nine generations onto the $\mathrm{C} 57 \mathrm{BL} / 6 \mathrm{~J}$ background. Animals for biochemical experiments were 1- to 3-d-old NCAM+/+ and NCAM-/- littermates from heterozygous breeding pairs. To prepare cultures of hippocampal neurons, 1- to 3-d-old C57BL/6J and NCAM-/- mice from homozygous breeding pairs were used. All experiments were conducted in accordance with the German and European Community laws on protection of experimental animals. All procedures used were approved by the responsible committees of The State of Hamburg and the University of New South Wales.

ELISA. Exo70 and sec8 $(100 \mu \mathrm{g} / \mathrm{ml})$ were immobilized overnight at $4^{\circ} \mathrm{C}$ on polyvinylchloride surface in 96 -well plates. Wells were then washed three times for 5 min each with Tris-buffered saline (TBS), $\mathrm{pH}$ 7.4 , containing $0.05 \%$ Tween (TBST), and blocked overnight at $4^{\circ} \mathrm{C}$ with $10 \%$ BSA in TBS. Wells were subsequently incubated with 140ID, 180ID, or NCAM-Fc applied at different concentrations (150 nM to $10 \mu \mathrm{M})$ in TBS at $4^{\circ} \mathrm{C}$ overnight. When indicated, 140ID was applied together with chemically synthesized $140 \mathrm{ID}_{748-777}, 140 \mathrm{ID}_{766-810}$, or $140 \mathrm{ID}_{729-750}$ peptides (Shafer-N). Wells were then washed three times for 5 min each with TBST. Bound proteins were detected with the antibodies against NCAM and the appropriate HRP-linked secondary antibodies. Protein binding was visualized by detecting HRP with the OPD reagent (Pierce) that resulted in colored product. The reaction was stopped with $2.5 \mathrm{M} \mathrm{H}_{2} \mathrm{SO}_{4}$. The amount of colored product was quantified using ELISA reader at $492 \mathrm{~nm}$.

In vitro phosphorylation. Recombinant FGF receptor 1 kinase was purchased from Cell Signaling Technology and used according to the manufacturer's instructions. His ${ }_{6}$-tagged sec8, sec8Y401F, sec8Y616F, and sec8Y401,616F were immobilized on Ni-NTA beads. For each phosphorylation reaction, $50 \mathrm{ng}$ of FGF receptor 1 kinase and $30 \mu \mathrm{l}$ of beads with the respective protein were combined in $50 \mu \mathrm{l}$ of kinase buffer $(60 \mathrm{mM}$ HEPES, $5 \mathrm{~mm} \mathrm{MgCl}_{2}, 5 \mathrm{~mm} \mathrm{MnCl}, 3 \mu \mathrm{M} \mathrm{Na} \mathrm{VO}_{4}, 200 \mu \mathrm{M}$ ATP, and 2.5 $\mathrm{mm}$ DTT) and incubated for $30 \mathrm{~min}$ at room temperature. The control reaction was performed in the absence of ATP or in the presence of the FGFR inhibitor PD173074 (100 nM, Merck). Beads were washed with TBS, centrifuged for $1 \mathrm{~min}$, and used for Western blot analysis.

Preparation of brain tissue homogenates. Homogenates of brains were prepared using a Potter homogenizer in HOMO buffer $\left[1 \mathrm{mM} \mathrm{MgCl}_{2}, 1\right.$ $\mathrm{mm} \mathrm{CaCl}_{2}, 5 \mathrm{~mm}$ Tris, pH 7.4, $0.1 \mathrm{~mm}$ PMSF, and EDTA-free protease inhibitor cocktail (Roche)] containing $0.32 \mathrm{M}$ sucrose (HOMO-A).

Isolation of growth cones and growth cone plasma membranes. Growth cones were isolated as described previously (Pfenninger et al., 1983). Brain homogenates from 1- to 3-d-old mice were centrifuged at $1660 \times$ $g$ for $15 \mathrm{~min}$ at $4^{\circ} \mathrm{C}$. The supernatant was collected and centrifuged on a discontinuous density gradient of $0.75 / 1.0 / 2.66 \mathrm{M}$ sucrose at 242,000 $\times \mathrm{g}$ for $30 \mathrm{~min}$ at $4^{\circ} \mathrm{C}$. The interface between the load and $0.75 \mathrm{~m}$ sucrose, containing growth cones, was collected, resuspended in $10 \mathrm{ml}$ of Homo-A buffer, and pelleted by centrifugation at 100,000 $\times g$ for $40 \mathrm{~min}$ at $4^{\circ} \mathrm{C}$ to obtain purified growth cones.

To obtain growth cone plasma membranes, growth cones were lysed by resuspending them in $5 \mathrm{ml}$ of $5 \mathrm{~mm}$ Tris- $\mathrm{HCl}, \mathrm{pH} 7.5$, and stirring on ice for $5 \mathrm{~min}$. Lysed growth cones were centrifuged at $100,000 \times g$ for 60 $\min$ at $4^{\circ} \mathrm{C}$. The pellet containing growth cone plasma membranes was resuspended in $5 \mathrm{~mm}$ Tris- $\mathrm{HCl}, \mathrm{pH} 7.5$.

Treatment of the isolated growth cones. Freshly isolated growth cones (1 $\mathrm{mg}$ of total protein) were resuspended in $150 \mu$ l of Homo-A buffer $(1 \mathrm{~mm}$ $\mathrm{MgCl}_{2}, 1 \mathrm{~mm} \mathrm{CaCl}, 5 \mathrm{~mm}$ Tris, and $0.32 \mathrm{~m}$ sucrose, $\mathrm{pH}$ 7.4) and incubated with the rabbit polyclonal antibodies against NCAM or nonspecific rabbit IgG for $5 \mathrm{~min}$ at $37^{\circ} \mathrm{C}$ with constant gentle shaking. When indicated, chicken polyclonal antibodies against NCAM and preimmune chicken serum were also used. Both antibodies produced similar results. Samples were then centrifuged at $100,000 \times g$ for $30 \mathrm{~min}$ at $4^{\circ} \mathrm{C}$. Pellets containing growth cones were collected and used for further analysis.

Recruitment of the exocyst complex subunits to the growth cone membrane. $\mathrm{NCAM}+/+$ brains were homogenized in $5 \mathrm{~mm}$ Tris- $\mathrm{HCl}$ buffer, $\mathrm{pH} 7.4$, and centrifuged at $100,000 \times g$ and $4^{\circ} \mathrm{C}$ for $1 \mathrm{~h}$. The supernatant (cytosol) was collected and used as a source of endogenous exocyst complex subunits.

When indicated, before the recruitment assay the growth cone membranes were treated with $0.1 \mathrm{M} \mathrm{Na}_{2} \mathrm{CO}_{3}$ for $8 \mathrm{~h}$ at $4^{\circ} \mathrm{C}$ to strip off peripheral proteins and any cytosolic proteins that may have copurified with the growth cone membranes and could thus interfere with the binding. Growth cone membranes were incubated for $2 \mathrm{~h}$ at room temperature with the cytosol ( $500 \mu \mathrm{g}$ of total protein) in a total assay volume of $1 \mathrm{ml}$ in the incubation buffer [0.25 mM Tris- $\mathrm{HCl}, 150 \mathrm{~mm} \mathrm{NaCl}, \mathrm{pH} 7.4$, and EDTA-free protease inhibitor cocktail (Roche)] or with incubation buffer only. Growth cone membranes were then collected by centrifugation at $100,000 \times g$ and $4^{\circ} \mathrm{C}$ for $1 \mathrm{~h}$ and washed by resuspending them in 500 $\mu l$ of incubation buffer and repeating the centrifugation. Pellets were resuspended in $50 \mu \mathrm{l}$ of incubation buffer. Recruitment of the exocyst complex subunits was detected by Western blot.

Analysis of exocytosis in growth cones. Unless otherwise indicated, all steps were performed on ice. Growth cones $(1.3 \mathrm{ml})$ collected at the load/0.75 $\mathrm{m}$ sucrose interface (see above, Isolation of growth cones and growth cone plasma membranes) were mixed with $0.5 \mathrm{ml}$ of $2 \times$ dilution buffer (100 mm sucrose, $20 \mathrm{~mm}$ glucose, $200 \mathrm{~mm} \mathrm{NaCl}, 10 \mathrm{~mm} \mathrm{KCl}, 2.4$ $\mathrm{mm} \mathrm{NaH}{ }_{2} \mathrm{PO}_{4}, 44 \mathrm{~mm}$ HEPES, and $2.4 \mathrm{~mm} \mathrm{MgCl}_{2}, \mathrm{pH} 7.3$ ), incubated for $30 \mathrm{~min}$, mixed with additional $0.8 \mathrm{ml}$ of the $2 \times$ dilution buffer, and incubated for $20 \mathrm{~min}$. This suspension $(250 \mu \mathrm{l})$ was added to assay tubes and preincubated with or without BAPTA-AM (30 $\mu \mathrm{M}$, Sigma), tetanus toxin (10 nM, Sigma), nifedipine (10 $\mu \mathrm{M}$, Alomone Labs), pimozide (5 $\mu \mathrm{M}$, Alomone Labs), dynasore (80 $\mu \mathrm{M})$, or PD173074 (100 nM, Merck) for $30 \mathrm{~min}$. Chicken polyclonal antibodies against NCAM or preimmune serum were added to the samples and samples were equilibrated for 15 min. Unless otherwise stated, samples were then warmed up in a water bath to $37^{\circ} \mathrm{C}$ for $5 \mathrm{~min}$, and subsequently chilled in ice slurry for $5 \mathrm{~min}$. Samples were then split into two groups, and one group was incubated for $5 \mathrm{~min}$ with saponin (final concentration $0.01 \%$ ) to permeabilize membranes. All samples were then incubated for 15 min with HRP- 
labeled cholera toxin $(0.03 \mu \mathrm{g} / \mathrm{ml})$ to label plasma membranes. Samples were then loaded onto $0.5 \mathrm{ml}$ cushions of $0.4 \mathrm{M}$ sucrose in TBS and centrifuged at $100,000 \times g$ at $4^{\circ} \mathrm{C}$ for $1 \mathrm{~h}$. Pellets were resuspended in 200 $\mu \mathrm{l}$ of water and HRP activity was measured using OPD reagent (Pierce). Hence, each experimental set included NCAM antibody- and preimmune serum-incubated growth cones, which were either permeabilized or nonpermeabilized before labeling with HRP-cholera toxin. HRP activity in permeabilized growth cones indicates the total membrane pool, while HRP activity in nonpermeabilized growth cones represents the surface membrane pool. The internal membrane pool was calculated as a difference between the total and surface membrane pools. Changes in the internal membrane pool were analyzed as a measure of vesicle exocytosis and compared between NCAM antibody-treated and preimmune serum-treated growth cones.

DNA constructs and recombinant proteins. Cherry, synaptobrevinpHluorin and DN-FGFR1 constructs were generously provided by Dr. Roger Tsien (University of California, San Diego, La Jolla, CA), Dr. Gero Miesenböck (Yale University School of Medicine, New Haven, CT), and Dr. Moira O'Bryan (Monash University, Melbourne, Australia). Intracellular domains of NCAM140 and NCAM180 were as described previously (Sytnyk et al., 2002; Leshchyns'ka et al., 2003). Intracellular domain of NCAM140 was used as template to produce NCAM140 fragments $1_{140 D_{729-750}}$ and $140 \mathrm{ID}_{777-810}$, which were cloned into the pcDNA3.1/ V5-His vector (Invitrogen) and used in analysis of the exocytosis in live neurons and neurite outgrowth assay.

To clone sec8, double-stranded cDNA was synthesized using SuperScript II RT (Invitrogen) from total RNA isolated from mouse brain by High Pure RNA Tissue Kit (Roche). Mouse sec8 was amplified from cDNA and cloned into pcDNA3.1/V5-His and pET100 vectors using corresponding TOPO Expression Kits (Invitrogen) according to the manufacturer's instructions. Sec8Y401F, sec8Y616F, and sec8Y401,616F mutants were generated using a PCR-mediated Site-Directed Mutagenesis Kit (Stratagene) with the following oligonucleotides: 5'-GCTGCAGATGCTGTTGACTGAATTCTTGGATATGAAG-3' for Y401F and 5'-GGTGTGTGTGAAGCTTCAGGAATACAAGGACACATGC-3' for Y616F. All constructs were verified by sequencing. His $_{6}$-tagged sec8, 140ID, and 180ID and GSTtagged exo70 were expressed in Escherichia coli and purified using Ni-NTA beads or glutathione beads, respectively (Bodrikov et al., 2005). The GST-tag was removed from exo70 by thrombin digestion (Guan and Dixon, 1991).

Coimmunoprecipitation. For coimmunoprecipitation experiments, samples containing $1 \mathrm{mg}$ of total protein were lysed for $1 \mathrm{~h}$ at $4^{\circ} \mathrm{C}$ with lysis buffer, pH 7.5, containing $50 \mathrm{~mm}$ Tris- $\mathrm{HCl}, 150 \mathrm{~mm} \mathrm{NaCl}, 1 \%$ Nonidet P-40, 1 mu Na${ }_{4} \mathrm{P}_{2} \mathrm{O}_{7}, 1 \mathrm{~mm} \mathrm{NaF}, 2 \mathrm{~mm} \mathrm{Na}_{3} \mathrm{VO}_{4}, 0.1 \mathrm{~mm}$ PMSF, and EDTA-free protease inhibitor cocktail (Roche). When indicated, 2 mM EDTA were added to the lysis buffer. For analysis of the coimmunoprecipitation of NCAM with Sec $8,0.5 \%$ SDS were added to the lysis buffer to improve solubilization of NCAM. Lysates were centrifuged for $15 \mathrm{~min}$ at $20,000 \times g$ at $4^{\circ} \mathrm{C}$. Supernatants were cleared with protein A/G-agarose beads (Santa Cruz Biotechnology) applied for $3 \mathrm{~h}$ at $4^{\circ} \mathrm{C}$ and incubated with corresponding antibodies or nonspecific IgG applied overnight at $4^{\circ} \mathrm{C}$. Complexes were then precipitated with protein $\mathrm{A} / \mathrm{G}-$ agarose beads applied for $3 \mathrm{~h}$ at $4^{\circ} \mathrm{C}$. Beads were washed four times with lysis buffer and three times with PBS, pH 7.4, and used for Western blot analysis.

Western blot analysis. Proteins were separated by $6-10 \%$ SDS-PAGE and electroblotted to Nitrocellulose Transfer Membranes (PROTRAN; Schleicher \& Schuell). The membranes were then incubated with appropriate primary antibodies followed by incubation with HRP-labeled secondary antibodies, which were visualized using ECL Western blotting reagents (GE Healthcare) or SuperSignal West Dura Extended Duration reagents (Pierce) on BIOMAX films (Sigma). Molecular weight markers were prestained protein standards from Bio-Rad. The chemiluminescence quantification was performed using TINA 2.09 software (University of Manchester, Manchester, UK) or Scion Image for Windows.

Cultures of hippocampal neurons and 3 T3 fibroblasts. Cultures of hippocampal neurons were prepared from 1 - to 3 -d-old mice. Neurons were grown for $24 \mathrm{~h}$ in Neurobasal A medium (Invitrogen) supplemented with 2\% B-27 (Invitrogen), glutamine (Invitrogen), and FGF-2 (2 ng/ml, R\&D Systems) on glass coverslips coated with poly-L-lysine $(100 \mu \mathrm{g} / \mathrm{ml})$.
3T3 fibroblasts were maintained in DMEM containing 10\% fetal bovine serum (Invitrogen). Fibroblasts and neurons were transfected with Lipofectamine 2000 (Invitrogen) in accordance with the manufacturer's instructions.

Immunofluorescence labeling. Immunolabeling was performed as described previously (Sytnyk et al., 2002). All steps were performed at room temperature and all antibodies were applied in 1\% BSA in PBS. Neurons were fixed for $15 \mathrm{~min}$ in $4 \%$ formaldehyde in PBS. This fixation procedure does not permeabilize membranes (Sytnyk et al., 2002). To label NCAM at the cell surface, fixed neurons were blocked with $1 \%$ BSA in PBS for 20 min. NCAM at the cell surface was detected with polyclonal antibodies against the NCAM extracellular domain applied for $30 \mathrm{~min}$ followed by corresponding secondary antibodies applied for $30 \mathrm{~min}$. Then neurons were postfixed for $5 \mathrm{~min}$ in $2 \%$ formaldehyde in PBS, washed with PBS, permeabilized with $0.25 \%$ Triton X-100 in PBS for 5 min, blocked with $1 \%$ BSA in PBS for $20 \mathrm{~min}$, and treated with primary antibodies against intracellular proteins indicated in the text for $2 \mathrm{~h}$ followed by corresponding secondary antibodies applied for $45 \mathrm{~min}$. Coverslips were embedded in Aqua-Poly/Mount (Polysciences). Images were acquired at room temperature using a confocal laser scanning microscope (LSM510), LSM510 software, and 40× objective with numerical aperture 1.4 (all from Zeiss).

Analysis of the exocytosis in live neurons. Neurons were cotransfected $6 \mathrm{~h}$ after plating with cherry, synaptobrevin-pHluorin, and constructs indicated in the text. Recordings of live neurons were performed using a time-lapse function of the laser scanning microscope LSM510. During recordings, neurons were maintained on the microscope stage in an incubator (Zeiss) at $37^{\circ} \mathrm{C}$ and $5 \% \mathrm{CO}_{2}$. Images were acquired with a $10 \mathrm{~s}$ interval. After taking 10 images, neurons were irreversibly photobleached with the high-intensity laser beam ( $488 \mathrm{~nm}, 100 \%$ output power), and recovery of pHluorin fluorescence was monitored. Cherry fluorescence was used to control focus and changes in neuronal morphology.

Immunofluorescence quantification. Neurites and growth cones were manually outlined in the ImageJ software (National Institutes of Health) and mean immunofluorescence intensities along neurites and in growth cones were measured within these outlines using ImageJ.

Neurite outgrowth assay. To visualize neurites, $\mathrm{NCAM}+/+$ and NCAM $-/-$ neurons were colabeled with antibodies against $\beta$ tubulin and tau, and only isolated neurons were analyzed. In transfection experiments, NCAM $+/+$ neurons were transfected with the indicated constructs $6 \mathrm{~h}$ after plating. Neurons were cotransfected with cherry to visualize neuronal morphology. NCAM antibodies and control nonspecific Ig were applied $8 \mathrm{~h}$ after transfection for $12 \mathrm{~h}$. Lengths of neurites were measured using ImageJ.

\section{Results}

\section{TGN-derived organelles abnormally accumulate in neurites} of NCAM-deficient neurons

Since NCAM binds to TGN-derived intracellular organelles (Sytnyk et al., 2002), we analyzed whether NCAM deficiency influences the distribution of TGN-derived organelles in growing neurites. Wildtype $(\mathrm{NCAM}+/+)$ and NCAM-deficient $(\mathrm{NCAM}-/-)$ hippocampal neurons maintained in culture for $1 \mathrm{~d}$ were immunolabeled with antibodies against $\gamma$-adaptin, a TGN-marker protein. Analysis of immunofluorescence images showed that the intensity of $\gamma$-adaptin immunofluorescence was increased in growth cones and along neurites of NCAM-/ - versus NCAM+/+ neurons (Fig. 1A).

The molecular markers MAP2 and tau were present in all neurites of these immature neurons (not shown) in accordance with previous reports (Sytnyk et al., 2002), precluding distinction between axons and dendrites at the molecular level. Morphological analysis showed, however, that $\gamma$-adaptin levels were increased both in prospective axons, identified as thin long neurites, and prospective dendrites, identified as thicker, shorter, and often tapering processes (Fig. $1 A$ ).

Interestingly, growth cones of NCAM-/- neurons were slightly enlarged probably as a result of the filling of neurites and growth 
A
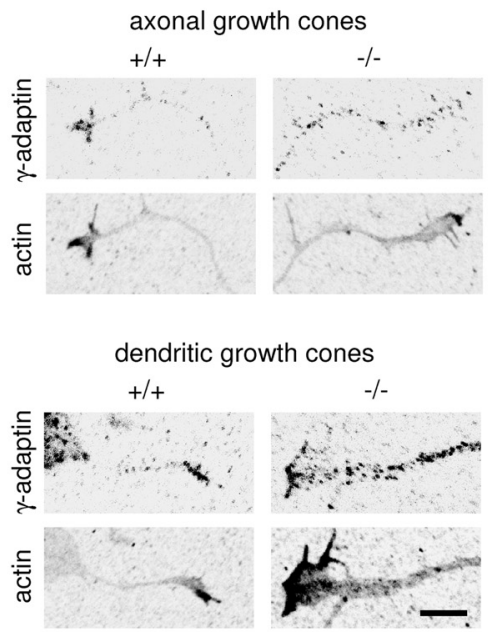

○̊
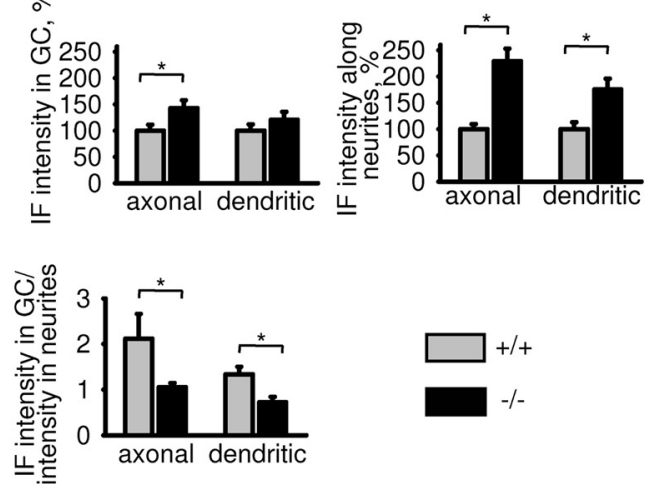

Figure 1. Distribution of the TGN-derived organelles is abnormal in NCAM $-/-$ neurites. $A$, Axons and dendrites of cultured $\mathrm{NCAM}+/+$ and NCAM - / - hippocampal neurons labeled with antibodies against $\gamma$-adaptin (TGN marker) and actin. Immunofluorescence signals are shown as grayscale inverted images to better visualize the distribution of TGN-derived organelles observed as accumulations of $\gamma$-adaptin. Note that numbers of $\gamma$-adaptin-positive organelles are increased in NCAM- $/-$ neurites, but their predominant accumulation in growth cones is impaired. Graphs show intensity of $\gamma$-adaptin immunofluorescence (IF) along neurites and in growth cones $(\mathrm{GC})$, and ratio of the $\gamma$-adaptin immunofluorescence intensity in growth cones to neurites (mean $+\mathrm{SEM}, n=100$ neurons from a representative experiment; immunofluorescence intensity values were normalized to the mean value in NCAM $+/+$ neurons set to $100 \%$; the same effect was observed in 3 independent experiments). Levels of actin used to visualize growth cones were not different in growth cones of both genotypes (not shown). Note that in NCAM $+/+$ neurites, the ratio of the $\gamma$-adaptin immunofluorescence intensity in growth cones to neurites is $>1$, indicating predominant accumulation of TGN-derived organelles in growth cones versus neurites. This ratio is $<1$ in NCAM $-/-$ neurites. ${ }^{*} p<0.05$ ( $t$ test). Scale bar, $10 \mu \mathrm{m} . \boldsymbol{B}, \mathrm{NCAM}+/+$ and NCAM $-/-$ growth cones and brain homogenates probed by Western blot with antibodies against GM130 and $\gamma$-adaptin. GAPDH served as loading control. Note that levels of GM130 and $\gamma$-adaptin are similar in NCAM $+/+$ and NCAM $-/-$ brain homogenates and increased in NCAM $-/-$ versus NCAM $+/+$ growth cones. $C$, Graph shows mean + SEM apparent boundary area of growth cones in $A$. Note that the apparent boundary area in NCAM $-/-$ versus $\mathrm{NCAM}+/+$ growth cones is increased. ${ }^{*} p<0.05$ ( $t$ test).

cones with TGN-derived organelles and widening of neurites proximally to the growth cones and/or unfolding of filopodia in growth cones (Fig. $1 A, C$ ). Since these changes in morphology may have affected the quantification of image analysis, we confirmed these data in cultured neurons by Western blot analysis of growth cones, which were isolated from the brain tissue of young (1- to 3-d-old) NCAM $-/-$ and NCAM+/+ mice (Pfenninger et al., 1983; Leshchyns'ka et al., 2003; Santuccione et al., 2005). Western blot analysis showed a similar effect: levels of $\gamma$-adaptin and GM130, a Golgi and TGN marker protein, were increased in NCAM-/- versus NCAM $+/+$ growth cones from the brain tissue by $34.1 \pm 8.1 \%$ and $64.3 \pm 18.4 \%$, respectively (from $n=4$ experiments, $p<0.05$, paired $t$ test, compared to NCAM $+/+$ probes) (Fig. $1 B$ ). Levels of GAPDH were not different in growth cones of both genotypes, indicating similar total protein loading (Fig. $1 B$ ). Overall levels of $\gamma$-adaptin and GM130 were not changed in total brain homogenates of $\mathrm{NCAM}-1-$ versus $\mathrm{NCAM}+/+$ mice $(109.3 \pm 11.1 \%$ and $108.9 \pm 6.8 \%$, respectively, NCAM+/+ levels were set to $100 \%$ ) (Fig. 1B). This observation excludes the possibility that increased levels of $\gamma$-adaptin and GM130 in NCAM-/- neurites and growth cones are due to the overall enhanced expression of these two proteins in NCAM - / - brains, suggesting abnormalities in organelle distribution.

A more detailed analysis of the immunofluorescence images also showed that NCAM deficiency affected not only levels but also distribution of $\gamma$-adaptin accumulations. In $\mathrm{NCAM}+/+$ neurons, $\gamma$-adaptin-positive organelles tended to accumulate in growth cones (Fig. 1A). This distribution was not observed in NCAM-/- neurons showing a more uniform distribution of the organelles (Fig. 1A). Similar results were obtained when neurons were labeled with antibodies against GM130 (not shown). Preferential accumulation in growth cones can be characterized by the ratio of $\gamma$-adaptin immunofluorescence intensities in growth cones to neurites, which was $>1$ for NCAM $+/+$ neurons (Fig. 1A). This ratio was reduced by $\sim 50 \%$ in NCAM $-/-$ neurons (Fig. $1 A)$. In contrast to the Golgi and TGN markers, the ratios of the levels of endosomal and lysosomal marker proteins EEA1 and Lamp1 in growth cones versus neurites were not significantly changed in NCAM-/- neurons (supplemental Fig. S1, available at www.jneurosci. org as supplemental material).

\section{NCAM interacts with subunits of the exocyst complex}

The exocyst complex plays a pivotal role in the polarized insertion of organelles in growing neurites by tethering organelles to the sites of exocytosis (Vega and Hsu, 2001; Hsu et al., 2004). In cultured hippocampal neurons, NCAM at the cell surface of growth cones partially colocalized with the exocyst subunit exo70, most prominently overlapping with this protein at the growth cone periphery as well as in filopodia and lamellipodia (Fig. 2A). Furthermore, exo70 and sec8 coimmunoprecipitated with NCAM from brain lysates (Fig. 2B). Approximately $27 \pm 10 \%$ of all exo70 molecules and $\sim 23 \pm 7 \%$ of all sec 8 molecules in 1 - to 3 -d-old mouse brain homogenates were found in a coimmunoprecipitation complex with NCAM. The efficiency of the coimmunoprecipitation of exo70 and sec8 with NCAM was reduced by $36.0 \pm 2.4 \%$ and $53 \pm 9.7 \%$, respectively, in the presence of $2 \mathrm{mM}$ EDTA (from $n=3$ experiments, $p<0.05$, paired $t$ test) (Fig. $2 B$ ), suggesting that the association of NCAM with the exocyst complex is regulated by divalent ions.

Next, we analyzed whether NCAM directly binds to the components of the exocyst complex by ELISA. Recombinant exo70 and sec8 immobilized on a plastic surface bound to the recombi- 
nant intracellular domain of the NCAM140 isoform (140ID) in a concentrationdependent manner (Fig. 2C). Exo70 and sec8 did not bind to the intracellular domain of the NCAM180 isoform (180ID) and extracellular domain of mouse NCAM fused to human Fc (NCAM-Fc) used as negative control (Fig. 2C).

Then, we examined the association of NCAM isoforms with the exocyst complex by coimmunoprecipitation from the brain tissue. Sec8 was immunoprecipitated from brain lysates (Fig. 2D). Exo70 coimmunoprecipitated with sec8, indicating that the whole exocyst complex was immunoprecipitated (Fig. 2D). In young brains, a high proportion of NCAM isoforms is polysialylated, as observed as a broad smear with an apparent molecular weight above $140 \mathrm{kDa}$ on Western blots (Fig. 2B,D, input) (Hoffman et al., 1982; Rothbard et al., 1982). However, Western blot analysis of sec 8 immunoprecipitates showed that only nonpolysialylated NCAM140, observed as a sharp $140 \mathrm{kDa}$ band, coimmunoprecipitated with $\sec 8$ (Fig. 2D).

To identify the binding sites for exo70 and sec 8 within $140 \mathrm{ID}$, chemically synthesized peptides derived from 140ID were used in a competition ELISA. 140ID ${ }_{729-750}$ but not $140 \mathrm{ID}_{748-777}$ or $140 \mathrm{ID}_{766-810} \mathrm{com}-$ pletely inhibited binding of 140ID to exo70 (Fig. 2E). Binding of 140ID to sec8 was partially inhibited by $140 \mathrm{ID}_{766-810}$ but not $140 \mathrm{ID}_{729-750}$ or $140 \mathrm{ID}_{748-777}$ (Fig. $2 \mathrm{E}$ ). Thus, exo70 and sec8 bind to 140ID at two distinct sites located at amino acids 729-750 and 777-810 of 140ID, respectively.

\section{NCAM promotes the recruitment of the exocyst complex to growth cone membranes}

Western blot analysis showed that exo70 and sec8 levels were reduced by $22.0 \pm$ $6.3 \%$ and $30.0 \pm 10.8 \%$, respectively, in growth cones isolated from NCAM $-/-$ brains (from $n=6$ experiments, $p<0.05$, paired $t$ test, compared to $\mathrm{NCAM}+/+$ probes) (Fig. $3 A$ ). This reduction was not due to overall decreased levels of the exocyst complex subunits in NCAM-/- brains. On the contrary, levels of exo70 and sec 8 were increased by $43.8 \pm 12.8 \%$ and $43.7 \pm$ $14.7 \%$, respectively, in NCAM-/- versus NCAM+/+ brain homogenates (from $n=6$ experiments, $p<0.05$, paired $t$ test, compared to NCAM+/+ probes) (Fig. $3 A$ ), suggesting a compensatory reaction to an abnormal disposition of the exocyst complex in NCAM - / - mice. The ratio of sec 8 and exo70 levels in growth cones to their levels in brain homogenates was reduced by $\sim 50 \%$ in $\mathrm{NCAM}-/-$ mice, indicating a significant reduction in the efficiency of targeting of the exocyst complex to growth cones. As control, levels of GAPDH were not affected in NCAM-/- probes.
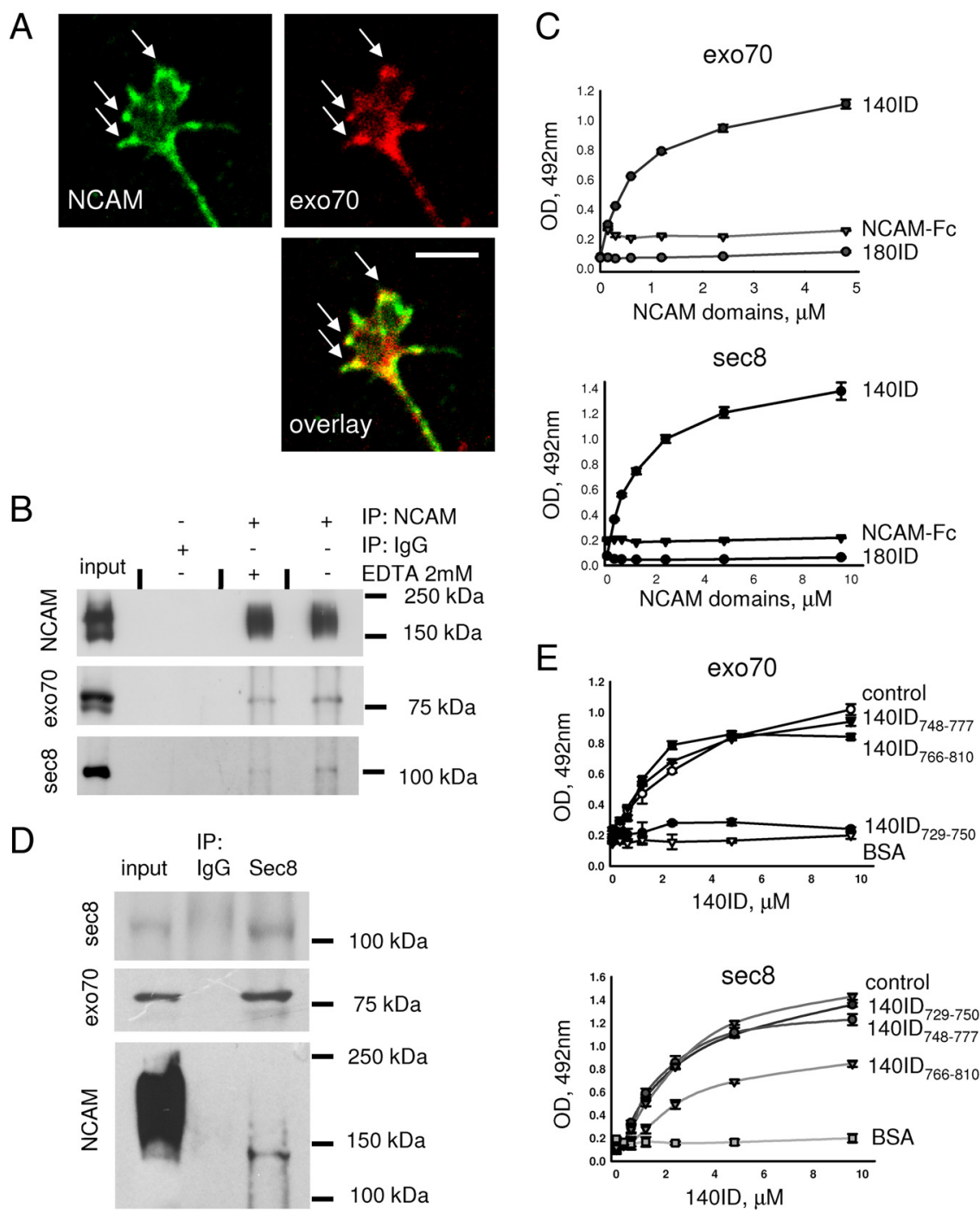

Figure 2. NCAM interacts with the exocyst complex. $A$, Growth cone of a 1-d-old cultured hippocampal neuron labeled with antibodies against NCAM and ex070. NCAM partially colocalizes with exo70 at the periphery of the growth cone (arrows). Scale bar, $5 \mu \mathrm{m} . \boldsymbol{B}$, NCAM immunoprecipitates (IP) from NCAM + / brain lysates and 10\% of input material (input) probed by Western blot with NCAM, exo70, and sec8 antibodies. Immunoprecipitation was performed in the presence or absence of 2 mM EDTA. Mock immunoprecipitation with nonspecific lgG served as control. Note that ex070 and sec 8 coimmunoprecipitate with NCAM and EDTA reduces the coimmunoprecipitation efficiency. C, Binding of 140ID, 180ID, or the extracellular domain of NCAM fused to human Fc (NCAM-Fc) to ex070 and sec8 immobilized on plastic analyzed by ELISA. Binding was detected with NCAM antibodies. Graphs show mean + SEM optical densities from a representative experiment $(n=3)$. Similar results were obtained in three independent experiments. Note that only $140 \mathrm{ID}$ bound to exo70 and sec 8 in a concentration-dependent manner. $D$, Sec 8 immunoprecipitates (IP) from NCAM + / brain lysates and 10\% of the input material (input) probed by Western blot with sec8, ex070, and NCAM antibodies. Here and in $\boldsymbol{B}$, a broad band of NCAM immunoreactivity above $140 \mathrm{kDa}$ represents polysialylated NCAM, which is strongly expressed in young brains. Note that only nonpolysialylated NCAM140 coimmunoprecipitated with sec8. $\boldsymbol{E}$, Binding of $140 \mathrm{ID}$ to ex070 and sec 8 as analyzed by ELISA. 140ID was applied alone (control) or together with $140 \mathrm{ID}_{748-777}, 140 \mathrm{ID}_{766-810}$, or $140 \mathrm{ID}_{729-750}$. Binding of 140ID to BSA served as a negative control (BSA). Binding was detected with NCAM (5B8) antibodies directed against the $C$-terminal region of $140 \mathrm{ID}$, which is distinct from $140 \mathrm{ID}_{748-777}, 140 \mathrm{ID}_{766-810}$, or $140 \mathrm{ID}_{729-750}$. Graphs show mean + SEM optical densities from a representative experiment $(n=3)$. Similar results were obtained in three independent experiments. Note that $140 \mathrm{ID}_{729-750}$ inhibits binding of $140 \mathrm{ID}$ to ex070, and $1401 \mathrm{D}_{766-810}$ inhibits binding of $140 \mathrm{ID}$ to sec 8 .

A similar result was obtained in cultured hippocampal neurons analyzed by immunofluorescence labeling: mean labeling intensities of exo70 and sec 8 measured in graphically outlined growth cones were reduced by $22.1 \pm 6.3 \%$ and $30.0 \pm 10.8 \%$, respectively, in NCAM $-/-$ versus $\mathrm{NCAM}+/+$ neurons (from $n=100$ neurons, $p<0.05$, $t$ test, reproduced in three independent experiments) (Fig. $3 B$ ), indicating lower levels of exo70 and sec8 expression per growth cone unit area. Similar results were obtained for axonal and dendritic growth cones. The ratio of 
A

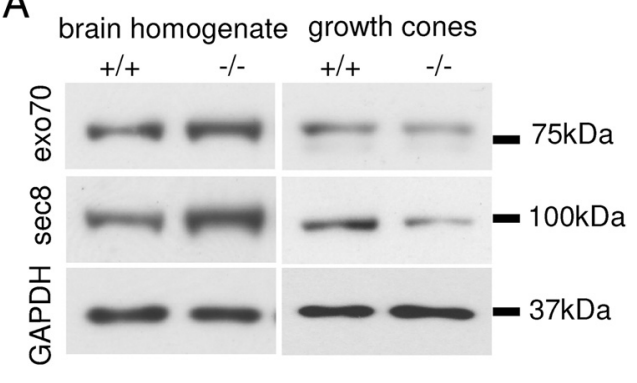

B
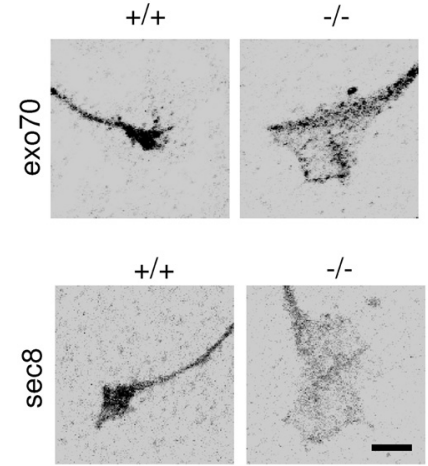

Figure 3. Targeting of the exocyst complex to growth cones is reduced in NCAM $-/-$ neurons. A, NCAM $+/+$ and NCAM - / - growth cones (GC) and brain homogenates (BH) probed by Western blot with ex070 and sec 8 antibodies. GAPDH served as loading control. Note that levels of ex070 and sec 8 are increased in NCAM $-/-$ brain homogenates and reduced in NCAM - / - growth cones. $B$, Axonal growth cones of cultured hippocampal neurons labeled with ex070 and sec 8 antibodies. Immunofluorescence signals are shown as grayscale inverted images. Note reduced levels of exo70 and sec 8 in NCAM - / - versus NCAM + / growth cones.

exo70 and sec8 immunofluorescence intensity in growth cones to exo70 and sec8 immunofluorescence intensity in neurites was significantly lower in NCAM $-/-$ versus $\mathrm{NCAM}+/+$ neurons $(1.75 \pm$ 0.06 vs $1.02 \pm 0.05$ for exo70 in NCAM $+/+$ and $\mathrm{NCAM}-/-$ neurons, respectively; $1.00 \pm 0.06$ vs $0.63 \pm 0.04$ for sec 8 in $\mathrm{NCAM}+/+$ and NCAM $-/-$ neurons, respectively; $p<0.05, t$ test).

To analyze whether NCAM deficiency influences levels of the exocyst complex specifically at the plasma membrane, plasma membranes isolated from $\mathrm{NCAM}+/+$ and $\mathrm{NCAM}-/-$ growth cones were analyzed by Western blot. Levels of the cell adhesion molecule L1, an integral membrane protein of the Ig superfamily, were similar in NCAM $+/+$ and NCAM $-/$ - growth cone membranes, indicating that growth cone membranes were isolated with a similar efficiency. However, significantly lower levels of exo70 and sec8 were coisolated with plasma membranes from NCAM $-/$ - versus NCAM +/+ growth cones (Fig. $4 A$ ), suggesting a lower efficiency of the exocyst complex attachment to NCAM $-/-$ membranes.

To estimate the efficiency of exocyst complex recruitment to plasma membranes, we incubated these from $\mathrm{NCAM}+/+$ and NCAM $-/-$ growth cones with soluble protein fraction (cytosol) from NCAM + / + brains as a source of endogenous exocyst complex subunits. The recruitment of exo70 and sec 8 from the cytosol to the membranes was then analyzed by Western blot. This analysis showed that the levels of exo70 and sec 8 that attached to $\mathrm{NCAM}+/+$ growth cone membranes were approximately twofold higher than the levels of these proteins recruited to NCAM $-/-$ membranes (Fig. 4A). A similar effect was also observed when, before the recruitment assay, the growth cone plasma membranes were treated with mild alkali to strip peripheral membrane proteins (Fig. 4A).
To analyze the role of the full-length NCAM140 in recruitment, the cytosol was preincubated with 140ID before the recruitment assay. The recruitment of exo70 and sec8 to $\mathrm{NCAM}+/+$ growth cone membranes was strongly inhibited by 140ID, but not 180ID or the intracellular domain of L1 used for comparison (Fig. 4B), indicating that recombinant 140ID competed with NCAM140 in plasma membranes for binding to exo70 and sec8. We conclude that NCAM140 promotes recruitment of the exocyst complex subunits to the growth cone plasma membrane.

\section{Exocyst complex assembly is not grossly affected in NCAM-/- brains}

To analyze whether the exocyst complex composition is affected by NCAM deficiency, coimmunoprecipitation of the exocyst complex subunits with each other was compared in brain homogenates from NCAM $-/-$ and NCAM $+/+$ mice. Sec8 coimmunoprecipitated with exo70 and exo70 coimmunoprecipitated with sec8 with a similar efficiency from $\mathrm{NCAM}+/+$ and NCAM $-/-$ brain lysates (in NCAM $-/-$ brains, the levels of exo70 coimmunoprecipitation with sec 8 were $95.1 \pm 3.7 \%$ and levels of sec 8 coimmunoprecipitation with exo70 were $104.2 \pm$ $2.3 \%$ of respective coimmunoprecipitation levels in NCAM $+/+$ brains, from $n=4$ experiments) (Fig. 5). Although we cannot exclude that the interactions between other subunits of the exocyst complex are affected by NCAM deficiency, these data suggest that the assembly of the exocyst complex is not grossly affected in NCAM - / - brains.

\section{NCAM regulates phosphorylation of the exocyst complex}

Little is known about the regulation of function of the exocyst complex. Hence, we analyzed whether the exocyst complex subunits are phosphorylated. Western blot analysis of sec 8 immunoprecipitates from NCAM $+/+$ brains with antibodies against phosphotyrosine residues showed that sec 8 was strongly phosphorylated at tyrosine(s). Tyrosine phosphorylation of sec8 was reduced by $73.6 \pm 6.3 \%$ in NCAM $-/-$ versus $\mathrm{NCAM}+/+$ brain homogenates (from $n=3$ experiments, $p<0.05$, paired $t$ test) (Fig. 6A). No detectable labeling with the phosphotyrosine antibodies was observed for exo70 immunoprecipitates from $\mathrm{NCAM}+/+$ or NCAM $-/-$ brain lysates (not shown).

We then investigated how phosphorylation would regulate exocyst complex function by analyzing the recruitment of exocyst complex subunits to NCAM $+/+$ growth cone membranes from the cytosol preincubated with staurosporine, a general inhibitor of kinases (Lebakken et al., 2007). Exo70 and sec8 from the staurosporine-treated cytosol attached to the growth cone membranes with an approximately twofold lower efficiency than from untreated cytosol (Fig. 6B), indicating that phosphorylation of the exocyst complex subunits is required for the efficient recruitment to growth cone membranes.

NCAM deficiency results in a strong downregulation of the activity of kinases involved in NCAM signaling, such as p59fyn tyrosine kinase (Bodrikov et al., 2005, 2008) and FGFR (Niethammer et al., 2002; Aonurm-Helm et al., 2010). We analyzed the role of these kinases by preincubating the cytosol with the respective inhibitors: PP2, an inhibitor of the src family tyrosine kinases and among them p59fyn, did not inhibit the recruitment of exo70 and sec8 to the membranes (Fig. 6B). However, the fibroblast growth factor receptor (FGFR) inhibitor PD173074 reduced the recruitment of exo70 and sec 8 to the membranes by $\sim 50 \%$ (Fig. $6 B)$.

Next, we analyzed whether binding of NCAM to extracellular ligands influences sec8 phosphorylation in growth cones. To 
mimic the binding of NCAM to homophilic and heterophilic extracellular ligands, growth cones isolated from $\mathrm{NCAM}+/+$ brains were incubated with polyclonal antibodies reacting with the extracellular domain of NCAM. We have chosen this approach because natural ligands of NCAM, such as NCAM itself, are less specifically targeted in their binding to NCAM, since they may interact with other molecules at the cell surface. We have also shown previously that NCAM antibodies induce intracellular signaling that is similar to that induced by extracellular domains of NCAM fused to human Fc (Bodrikov et al., 2008).

In growth cones incubated with NCAM antibodies, levels of tyrosine phosphorylated sec8 were approximately two times higher than in growth cones treated with nonspecific immunoglobulins (Fig. 6C), indicating that NCAM triggering by the antibodies at the cell surface induces $\sec 8$ phosphorylation. This effect was completely abolished by the FGFR inhibitor (Fig. 6C).

A comparison of the sequences of the FGFR and sec 8 showed that sec 8 contains two tyrosine residues at positions Y401 and Y616 showing similarity to the FGFR Y769 autophosphorylation site (Fig. 7A) (Mohammadi et al., 1991). To analyze whether FGFR phosphorylates sec8, nonmutated sec8 (sec8wt) and sec $8 Y 401 \mathrm{~F}$, sec8Y616F, and sec8Y401,616F mutants were subjected to the in vitro kinase assay with the FGFR kinase domain. This analysis showed that sec8wt was phosphorylated by the FGFR kinase domain in the presence of ATP (Fig. 7A). This effect was completely blocked in the absence of ATP or in the presence of the FGFR inhibitor (Fig. 7A). Tyrosine phosphorylation was partially inhibited in the point mutants sec8Y401F and sec8Y616F and blocked in sec8Y401,616F (Fig. 7A).

To corroborate our data with the FGFR inhibitor, we analyzed sec8 phosphorylation in 3T3 fibroblasts cotransfected with NCAM140 and dominant-negative DN-FGFR1 lacking the intracellular kinase domain (Cotton et al., 2006) but containing the extracellular portion of the FGFR1 receptor, which bears the NCAM binding site (Kiselyov et al., 2003). While phosphorylation of sec8 was strongly enhanced in fibroblasts transfected with NCAM140 only (Fig. 7B), NCAM-dependent phosphorylation of sec8 was blocked in cells cotransfected with NCAM140 and DNFGFR1 (Fig. 7B). Phosphorylation of sec 8 was also inhibited in fibroblasts cotransfected with sec8Y401,616F mutant (Fig. 7B), suggesting that sec8Y401,616F mutant competes in a dominantnegative manner with endogenous sec 8 for binding to the NCAM/FGFR complex. In agreement, levels of sec8 coisolated with membranes were higher in NCAM140/sec8Y401,616Fcotransfected fibroblasts when compared to NCAM140-onlytransfected fibroblasts or NCAM-negative fibroblasts, indicating that tyrosine mutation of sec 8 did not interfere with its recruitment to the membranes (Fig. 7C). Levels of exo70 were, however, reprobes).
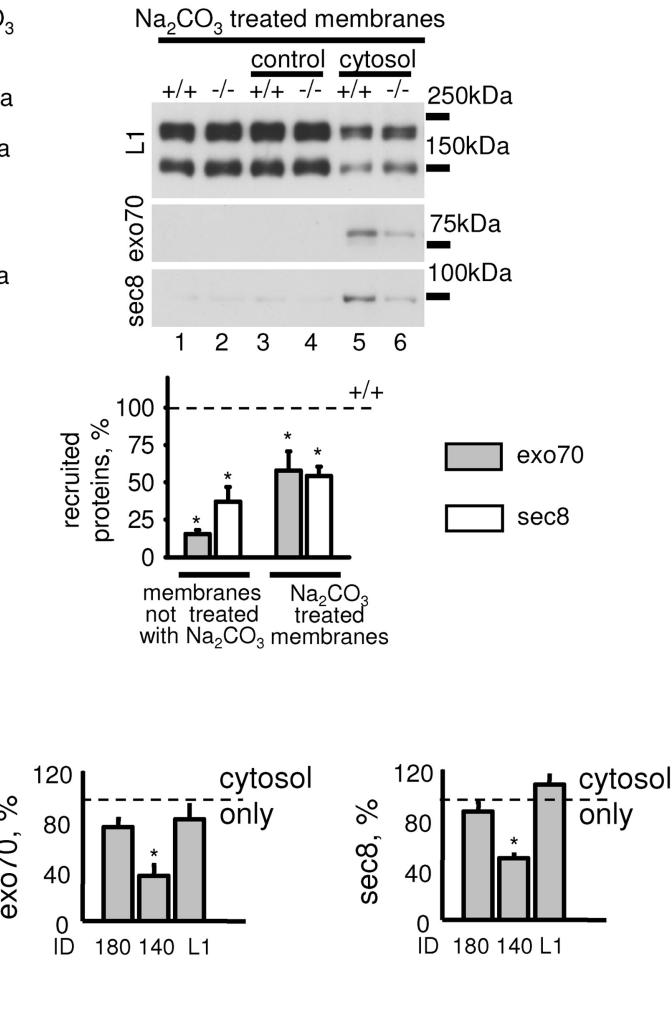

Figure 4. NCAM recruits the exocyst complex to growth cone membranes. $\boldsymbol{A}$, Recruitment of exo70 and sec8 from $\mathrm{NCAM}+/+$ cytosol to NCAM + / + and NCAM - / - growth cone membranes analyzed by Western blot with ex070 and sec 8 antibodies. Control membranes were incubated with the buffer used for cytosol preparation. Labeling for L1 served as (left) or growth cone membranes treated with alkali to strip NCAM $+/+$ levels set to $100 \%$ (dashed lines) from three experiments. ${ }^{*} p<0.05$ (paired $t$ test, compared to $+/+$ cytosol was preincubated with 180ID, 140ID, or L1ID. Note that recruitment is inhibited in the presence of 140ID (lane 4). ( SEM optical densities in 180ID-, 140ID-, and L1ID-treated probes normalized to the levels obtained with the cytosol only set to $100 \%$ (dashed line) from three experiments. ${ }^{*} p<0.05$ (paired $t$ test, compared to cytosol-only

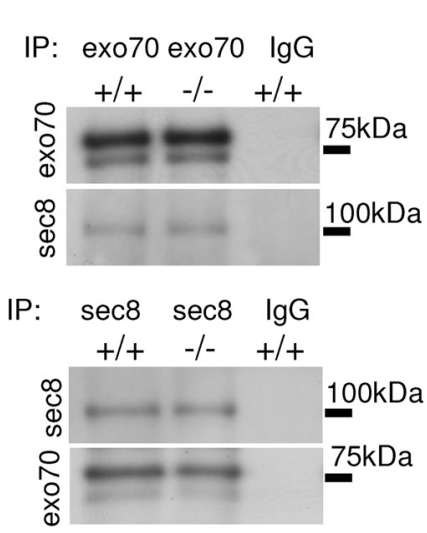

Figure 5. The association of sec 8 with exo70 is not affected in NCAM - / - brains. Ex070 and sec 8 immunoprecipitates (IP) from NCAM + / + and NCAM - / - brain lysates probed by Western blot with ex070 and sec 8 antibodies. Note that similar levels of sec 8 coimmunoprecipitate with ex070, and similar levels of ex070 coimmunoprecipitate with sec8 from NCAM + / + and NCAM - / - brain lysates. Mock immunoprecipitation with nonspecific lgG served as control. 
A IP: $\quad \sec 8 \quad \sec 8 \quad \lg G$
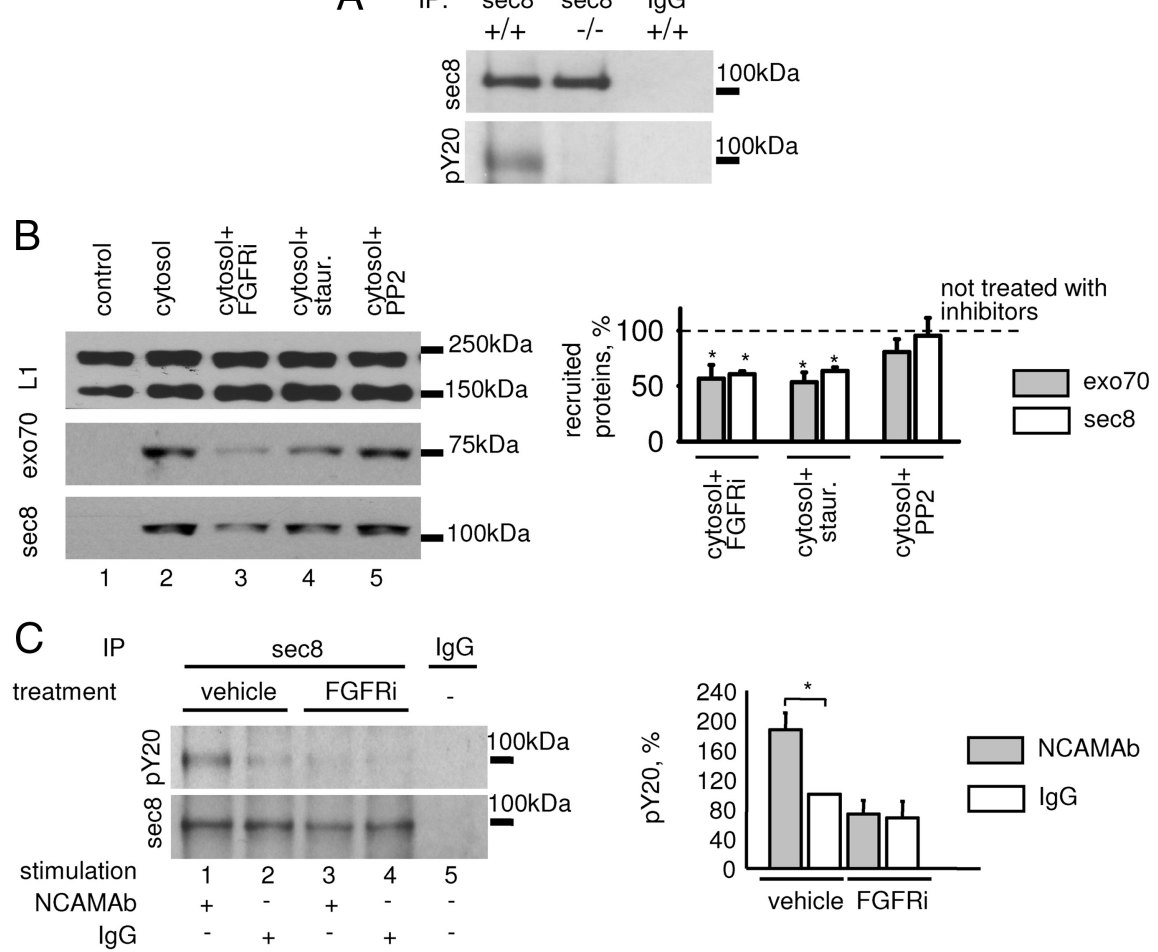

Figure 6. NCAM promotes phosphorylation of the exocyst complex by the FGF receptor. $A$, Sec 8 immunoprecipitates (IP) from $\mathrm{NCAM}+/+$ and NCAM $-/-$ brain lysates probed by Western blot with sec8 and phosphotyrosine antibodies (pY20). Mock immunoprecipitation with nonspecific lgG served as control. Note that tyrosine phosphorylation of sec 8 is reduced in NCAM - Ibrains. $\boldsymbol{B}$, Recruitment of ex070 and sec 8 from NCAM + / + cytosol to NCAM + / + growth cone membranes analyzed by Western blot with ex070 and sec 8 antibodies. Membranes were treated with alkali to strip peripheral proteins. Control membranes were incubated with the buffer used for cytosol preparation instead of cytosol. When indicated, the cytosol was preincubated with staurosporine, FGFR inhibitor PD173074, or src family inhibitor PP2. Labeling for L1 served as a loading control. Note that staurosporine (lane 4) and PD173074 (lane 3), but not PP2 (lane 5) inhibit recruitment of exo70 and sec8. Graph shows mean + SEM optical densities from 3 experiments. Levels in inhibitor-treated probes normalized to inhibitor nontreated probes (set to $100 \%$, dashed line) are shown. ${ }^{*} p<0.05$ (paired $t$ test, compared to probes nontreated with inhibitors). $C$, Sec 8 immunoprecipitates from NCAM $+/+$ growth cones analyzed by Western blot with sec 8 and pY20 antibodies. Mock immunoprecipitation with nonspecific mouse lg Gserved as control. Growth cones were treated with NCAM antibodies or nonspecific rabbit lgG in the presence or absence of the FGFR inhibitor. Note that the NCAM antibodies induce tyrosine phosphorylation of sec 8 (lane 1), which is blocked by the FGFR inhibitor (lane 3). Graph shows mean + SEM optical densities from three experiments with the signals for nonspecific rabbit lgG-treated growth cones set to $100 \%{ }^{*} p<0.05$ (paired $t$ test).

duced in membranes from NCAM140/sec8Y401,616F versus NCAM140-only-transfected fibroblasts (Fig. 7C), suggesting that the sec8Y401,616F mutant interferes with the exocyst complex assembly on the membranes.

\section{Binding of NCAM to extracellular ligands promotes NCAM/} exocyst complex formation and exocytosis in growth cones

To analyze whether triggering of NCAM by binding to extracellular ligands influences its interaction with the exocyst complex, growth cones isolated from NCAM+/+ brains were incubated with polyclonal antibodies against NCAM. The levels of exo70 and sec8, which coimmunoprecipitated with NCAM from these growth cones, were increased by $106.2 \pm 30.5 \%$ and $120.8 \pm 32.1 \%$, respectively, when compared to growth cones treated with nonspecific immunoglobulins (from $n=3$ experiments, $p<0.05$, paired $t$ test) (Fig. $8 A$ ), showing that the association of NCAM with the exocyst complex was enhanced in response to binding of the NCAM antibodies to NCAM at the growth cone surface.

Next, we analyzed whether exposure to NCAM antibodies influences the size of the internal membrane pool in isolated growth cones. A reduction in the internal membrane pool, rep- resenting intracellular membranous organelles, can be regarded as a measure of vesicle exocytosis in isolated growth cones. Cholera toxin, which binds predominantly and with high affinity to the plasma membrane-enriched ganglioside GM1, was used to label growth cone surface membranes only in nonpermeabilized growth cones and to label the total pool of membranes in detergent-permeabilized growth cones. The internal membrane pool was identified as the difference between the total and surface membrane pools. Incubation of growth cones with NCAM antibodies at $37^{\circ} \mathrm{C}$ resulted in an approximately twofold reduction in the internal membrane pool when compared to growth cones treated with preimmune serum (Fig. $8 B$ ). No change in the intracellular membrane pool in response to NCAM antibodies was observed in NCAM - / - growth cones (Fig. $8 B)$ or $\mathrm{NCAM}+/+$ growth cones treated with antibodies at $4^{\circ} \mathrm{C}$ (Fig. $8 \mathrm{C}$ ), indicating the specificity of the effect exerted by NCAM antibodies. NCAM antibodyinduced depletion of the internal membrane pool was blocked in growth cones preincubated with the tetanus toxin, which cleaves synaptobrevin, a component of the SNARE complex (Fig. 8C). A similar effect was observed in growth cones treated with the membrane-permeable form of the $\mathrm{Ca}^{2+}$ chelator BAPTA (Fig. $8 \mathrm{~B}$ ) and the FGFR inhibitor (Fig. 8D). Therefore, SNARE complex function, $\mathrm{Ca}^{2+}$ influx, and FGFR activation are required for NCAM antibody-induced vesicle exocytosis.

In developing neurons, binding of extracellular ligands to NCAM, and thus triggering of NCAM functions, induces $\mathrm{Ca}^{2+}$ influx into the cytosol via voltagedependent $\mathrm{Ca}^{2+}$ channels (VDCCs) of the T- and L-types (Williams et al., 1994; Kiryushko et al., 2006; Bodrikov et al., 2008). NCAM antibody-induced depletion of the internal membrane pool was completely blocked by nifedipine, a blocker of L-type VDCC, but not pimozide, a blocker of T-type VDCC (Fig. 8D). The internal membrane pool was increased when growth cones were treated with NCAM antibodies in the presence of nifedipine (Fig. 8D). This increase in the internal membrane pool could be explained by enhanced endocytosis since this effect was blocked in growth cones preincubated with nifedipine together with dynasore, an inhibitor of dynamin-dependent endocytosis (Macia et al., 2006) (Fig. 8E). Application of NCAM antibodies to growth cones in the presence of dynasore alone resulted in an $\sim 30 \%$ larger decrease in the internal membrane pool than when growth cones were treated with NCAM antibodies only (Fig. $8 E$ ). These observations suggest that NCAM-induced exocytosis is partially counterbalanced by endocytosis.

\section{NCAM promotes compartmentalized exocytosis in growth cones}

Next, we analyzed exocytosis in live 1- to 2-d-old cultured hippocampal neurons. Since exocyst- and NCAM-induced exocyto- 
FGFR2 (mouse) Y769-p: --TLTTNEEYLDLTQPL-sec8 (mouse) Y401-p: --LQMLLTEYLDMKNT-sec8 (mouse) Y616-p: --VCVKLQEYKDTCST--
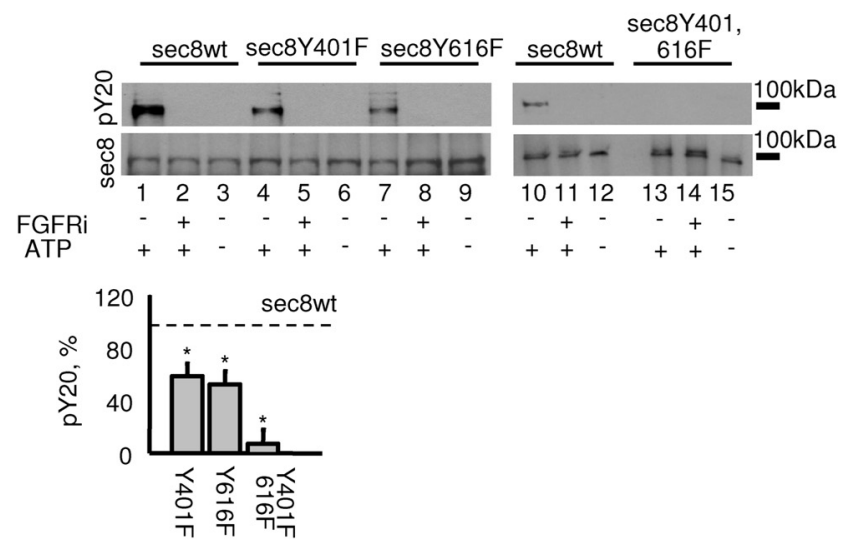

B

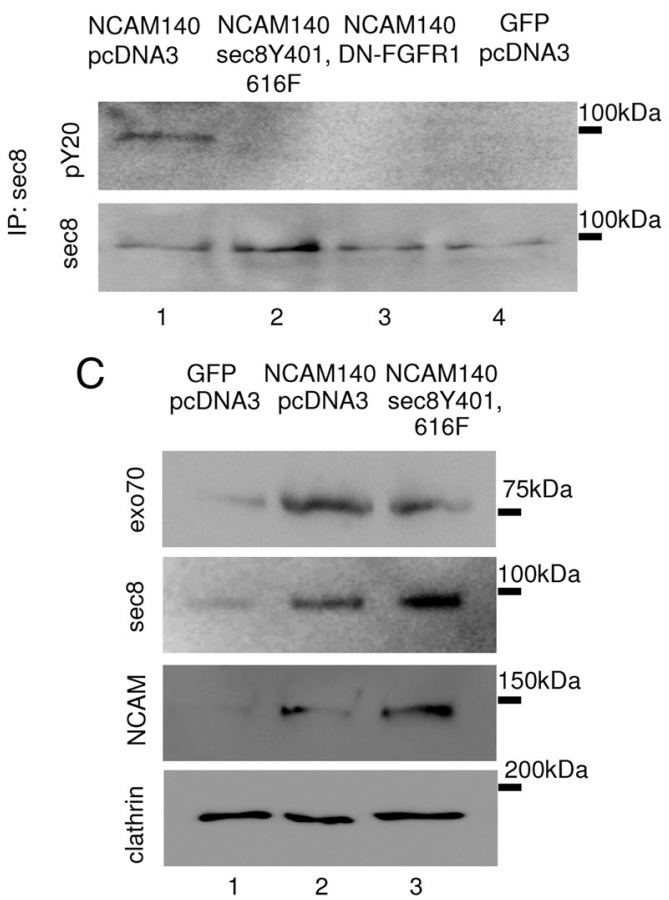

Figure 7. FGFR phosphorylates sec 8 at the tyrosine residues $Y 401$ and $Y 616$. $A$, Tyrosine phosphorylation of sec 8 analyzed by Western blot with sec 8 and pY20 antibodies. Sec 8 was incubated with the recombinant FGFR kinase domain in the presence or absence of ATP or FGFR inhibitor. Note that tyrosine phosphorylation of sec 8 with mutated Y 401 (lane 4) and Y616 (lane 7) is inhibited when compared to nonmutated sec8 (lane 1). Tyrosine phosphorylation of sec8Y401,616F is blocked (lane 13). A comparison of amino acid sequences surrounding the $Y 769$ autophosphorylation site in FGFR2, and Y401 and Y616 in sec8 is shown at the top. Graph shows mean + SEM phosphorylation levels of sec 8 mutants from three experiments normalized to sec 8 wt phosphorylation levels set to $100 \%$ (dashed line). ${ }^{*} p<0.05$ (paired $t$ test, compared to sec 8 wt levels). $B$, Sec 8 immunoprecipitates from $3 \mathrm{~T} 3$ fibroblasts transfected as indicated were analyzed by Western blot with sec 8 and pY20 antibodies. Note that tyrosine phosphorylation of sec 8 is increased in fibroblasts cotransfected with NCAM140 (lane 1) versus NCAM-negative fibroblasts (lane 4) and is inhibited in cells cotransfected with sec8Y401,616F (lane 2) and DN-FGFR1 (lane 3). C, Membranes isolated from 3T3 fibroblasts transfected as indicated were analyzed by Western blot with antibodies against sec8, ex070, and NCAM. Note that levels of ex070 and sec 8 are increased in membranes from NCAM140 transfected (lane 2) versus NCAM-negative (lane 1) fibroblasts. Levels of membrane-associated sec 8 are further increased in cells cotransfected with the sec $8 \mathrm{Y} 401,616 \mathrm{~F}$ mutant (lane 3 ), which is also recognized by sec 8 antibody (see $\boldsymbol{A}$ ). Levels of membrane-associated exo 70 are reduced in cells cotransfected with sec8Y401,616F. Labeling for clathrin served as loading control. sis involve the SNARE complex (Novick et al., 2006) (Fig. 8C), the sites of the exocytosis in live neurons were visualized by overexpressing a component of the SNARE complex, synaptobrevin, fused to pHluorin, a pH-sensitive form of GFP (Miesenböck et al., 1998): pHluorin is inactivated in the acidified environment of the vesicle lumen and is fluorescent only after exocytosis and exposure to the culture medium. In 1- to 2-d-old transfected neurons, synaptobrevin-pHluorin fluorescence was observed along all neurites and somata, indicating high levels of this protein at the neuronal surface (Fig. 9A). To visualize sites of new membrane insertion, synaptobrevin-pHluorin fluorescence was irreversibly photobleached and appearance of new pHluorin fluorescence spots was monitored with time. We found that synaptobrevin-pHluorin was highly mobile in the surface membrane of neurons (not shown) and photobleaching of a portion of a neuron always resulted in a recovery of pHluorin fluorescence by diffusion of synaptobrevin-pHluorin from nonphotobleached regions. To exclude diffusion-related recovery of pHluorin fluorescence, all neurites and somata of each neuron were irreversibly photobleached.

In NCAM $+/+$ neurons, new pHluorin spots appeared at the tips of neurites, i.e., in growth cones, and in discrete patches along neurites and somata (Fig. 9A; supplemental Video $S 1$, available at www.jneurosci.org as supplemental material). At the end of recordings, pHluorin fluorescence intensity in growth cones was on average two times higher when compared to adjacent segments of neurites (Fig. $9 \mathrm{~B}$ ) and recovered approximately by $40 \%$ of the intensity before photobleaching (Fig. 9C). By contrast, in NCAM $-/-$ neurons pHluorin fluorescence recovered in a diffuse manner over the total neuronal surface without preference to growth cones (Fig. 9A; supplemental Video S2, available at www.jneurosci.org as supplemental material). The recovery efficiency in growth cones was $\sim 2$ times lower in NCAM $-/-$ versus NCAM $+/+$ neurons (Fig. 9B, C). Synaptobrevin-pHluorin exocytosis was also impaired in NCAM $+/+$ neurons cotransfected with sec8Y401,616F: in these neurons, weak and diffuse recovery of pHluorin fluorescence was observed around the soma (Fig. 9; supplemental Video S3, available at www.jneurosci.org as supplemental material). In contrast, cotransfection with sec $8 \mathrm{wt}$ did not show any inhibitory effect (Fig. 9; supplemental Video S4, available at www.jneurosci.org as supplemental material). Compartmentalization and efficiency of exocytosis in growth cones

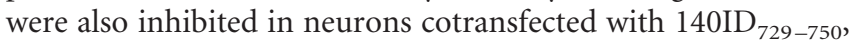
and, to a lower extent, $140 \mathrm{ID}_{777-810}$ (Fig. $9 B-D$ ), indicating that binding of exo70 and sec8 to NCAM140 is important for exocytosis in growth cones. It is conceivable that the reduced effect of $140 \mathrm{ID}_{777-810}$ on exocytosis is due to a lower efficiency with which this peptide inhibits binding of 140ID to sec8 (Fig. 2E).

\section{The exocyst complex is required for NCAM-dependent neurite outgrowth}

A comparison of cultured NCAM $+/+$ and NCAM- $-1-$ hippocampal neurons maintained for $24 \mathrm{~h}$ in vitro showed that neurite outgrowth in NCAM $-/-$ neurons was reduced (total length of all neurites per neuron was $48.7 \pm 3.9 \mu \mathrm{m}$ in NCAM $+/+$ neurons versus $26.65 \pm 1.8 \mu \mathrm{m}$ in NCAM $-/-$ neurons, from $n=100$ neurons, $p<0.05, t$ test) (Fig. 10A), suggesting that growth cone targeting of the exocyst complex is required for the efficient neurite outgrowth.

To analyze whether an acute interference with the exocyst complex function will also affect neurite outgrowth, NCAM $+/+$ neurons were transfected with the fluorescent protein cherry alone or cotransfected with 140ID peptides or sec8Y401,616F. 

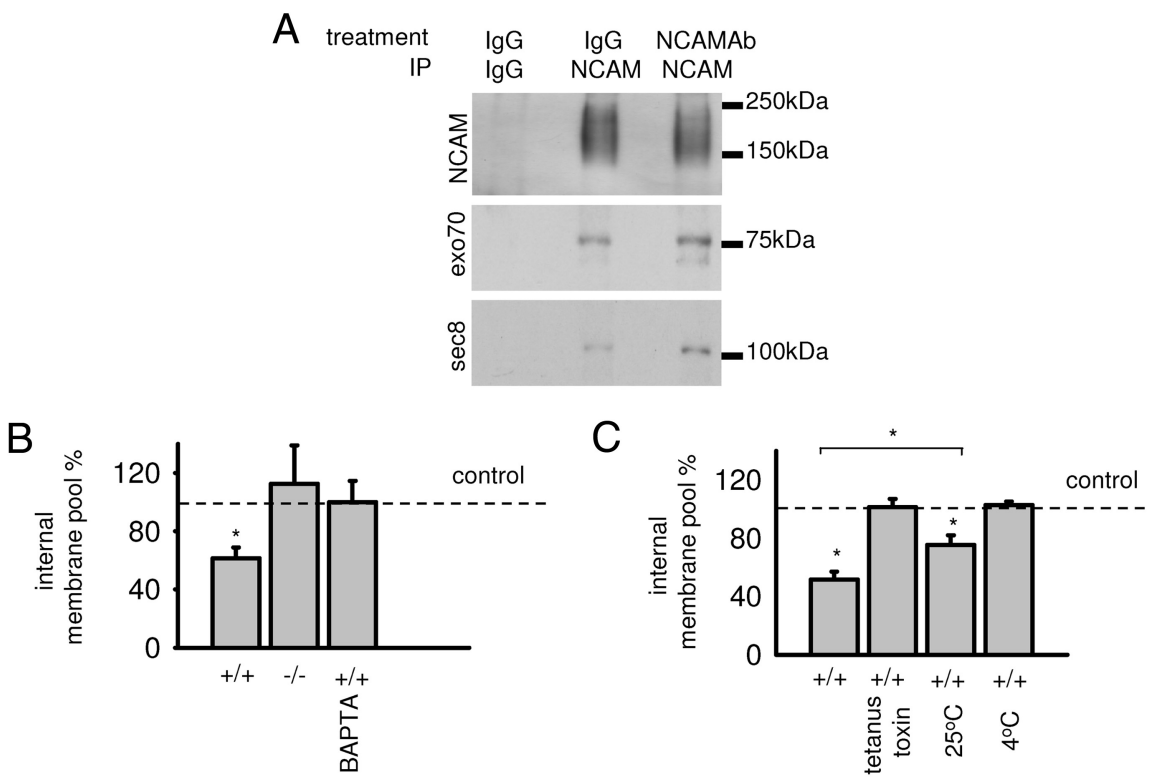

$\mathrm{D}$

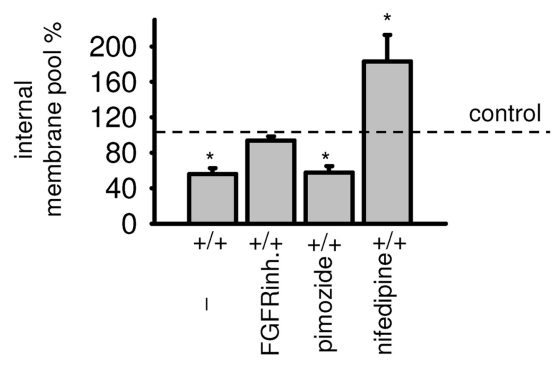

$\mathrm{E}$

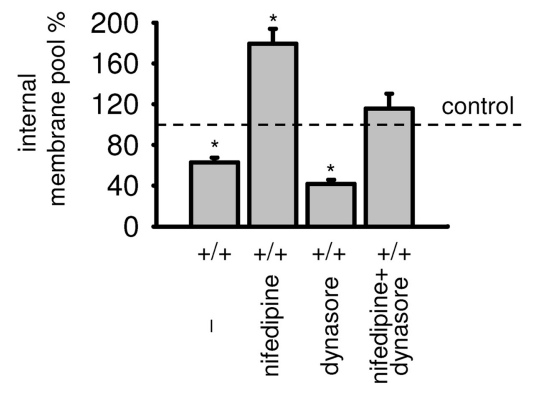

Figure 8. Specific triggering of NCAM functions by application of NCAM antibodies to isolated growth cones enhances the association of NCAM with the exocyst complex and induces depletion of the internal membrane pool.A, NCAM immunoprecipitates from NCAM + / growth cones analyzed by Western blot with NCAM, ex070, and sec8 antibodies. Mock immunoprecipitation with nonspecific lgG served as control. Growth cones were pretreated with nonspecific rabbit lgG or NCAM antibodies to cluster NCAM at the surface of growth cones. Note that coimmunoprecipitation of ex070 and sec8 with NCAM is increased in NCAM antibody-treated growth cones. $\boldsymbol{B}-\boldsymbol{E}$, Graphs show internal membrane pools in NCAM antibody-treated growth cones (mean + SEM from 3 experiments) normalized to the size of the internal membrane pool in preimmune serum-treated growth cones set to $100 \%$ (dashed line). Note that the internal membrane pool is reduced in NCAM + / + growth cones treated with NCAM antibodies, an effect that is blocked in NCAM $+/+$ growth cones pretreated with BAPTA $(\boldsymbol{B})$, tetanus toxin $(\boldsymbol{C})$, or the FGFR inhibitor and the L-type VDCC inhibitor nifedipine (D) or when growth cones were treated with NCAM antibody at $25^{\circ} \mathrm{C}$ or $4^{\circ} \mathrm{C}(\boldsymbol{C})$. NCAM-Igrowth cones served as control $(\boldsymbol{B})$. Inhibitor of T-type VDCC pimozide (D) does not influence, while inhibitor of dynamindependent endocytosis dynasore $(\boldsymbol{E})$ increases, the effect of NCAM antibodies. ${ }^{*} p<0.05$ (paired $t$ test, compared to preimmune serum-treated growth cones, or as indicated).

Neurons were then treated with nonspecific immunoglobulins or NCAM antibodies to induce NCAM-mediated neurite outgrowth (Bodrikov et al., 2008). Interestingly, basal nonspecific neurite outgrowth on poly-L-lysine in the presence of nonspecific immunoglobulins was not significantly affected by 140ID peptides or sec8 mutant (Fig. 10B), suggesting that noncompartmentalized exocytosis in neurons transfected with $140 \mathrm{ID}_{729-750}, 140 \mathrm{ID}_{777-810}$, or sec8Y401,616F is sufficient to maintain basal rates of neurite outgrowth. In agreement, diffuse exocytosis over neuronal somata and neurites was only mildly affected by $140 \mathrm{ID}_{729-750}, 140 \mathrm{ID}_{777-}$ 810 , or sec $8 Y 401,616 \mathrm{~F}$ (Fig. 9D). It should be noted here that transfection-associated manipulations of neurons always resulted in a slight inhibition of basal neurite outgrowth rates in all groups, possibly obscuring potential effects of the transfected constructs on basal neurite outgrowth. However, while NCAM antibody application resulted in an approximately twofold longer neurites in cherryonly-transfected neurons when compared to nonspecific Ig-treated neurons (Fig. 10B), this NCAM-dependent neurite outgrowth was strongly inhibited in neurons cotransfected with $1_{140 \mathrm{ID}_{729-750}}$, $140 \mathrm{ID}_{777-810}$, or sec8Y401,616F (Fig. $10 \mathrm{~B}$ ), indicating that compartmentalized exocytosis is essential for NCAMdependent neurite outgrowth. Notably, NCAM-dependent neurite outgrowth was even higher in neurons overexpressing sec8wt when compared to cherry-onlytransfected neurons (Fig. 10B). NCAM antibody-induced neurite outgrowth was inhibited in NCAM $+/+$ neurons transfected with dominant-negative DN-FGFR1 (Fig. 10C), confirming that FGFR activity is required for NCAM-dependent neurite outgrowth.

\section{Discussion}

The exocyst is a protein complex that has been found to be essential for exocytosis underlying neurite outgrowth (Hsu et al., 2004). Several models have been proposed to explain how the exocyst complex promotes exocytosis, including modulating cytoskeletal activity and tethering vesicles to the plasma membrane. Targeting of the exocyst complex to spatially defined domains, such as growth cones, is expected to be essential for a focused function of the exocyst complex. In this regard, exocyst subunits have been found to associate with various scaffold proteins such as PSD95 and SAP102 that target plasma membrane proteins to specific plasma membrane subdomains (Riefler et al., 2003; Sans et al., 2003) or with plasma membrane receptors, such as the glycine receptor GLYT1 (Cubelos et al., 2005).

In this manuscript, we identify NCAM as a novel binding partner of the exocyst complex. Several studies have shown that NCAM plays an important role in neural development by regulating neurite outgrowth. In agreement, NCAM-deficient mice show abnormalities in axonal growth and fasciculation in the hippocampus (Cremer et al., 1997; Seki and Rutishauser, 1998). Furthermore, inhibition of the homophilic interactions of NCAM by the secreted extracellular domain of NCAM results in impaired development of GABAergic basket interneurons in the prefrontal cortex (Brennaman and Maness, 2008), indicating that NCAM plays an important role in regulation of neurite outgrowth and neuronal development in vivo. Previously, changes in cytoskeleton dynamics and gene expression were considered to be the major mechanisms by which NCAM influences neurite outgrowth. In the present study, we expand the repertoire of NCAM functions and show a novel mechanism by which NCAM influences neurite outgrowth, namely, by exocyst-dependent delivery of membrane structures to the cell surface of growing neurites-a critical step in the process of neurite outgrowth.

NCAM, which accumulates at the surface of growth cones and mediates the interactions between neurons and adjacent cells and 

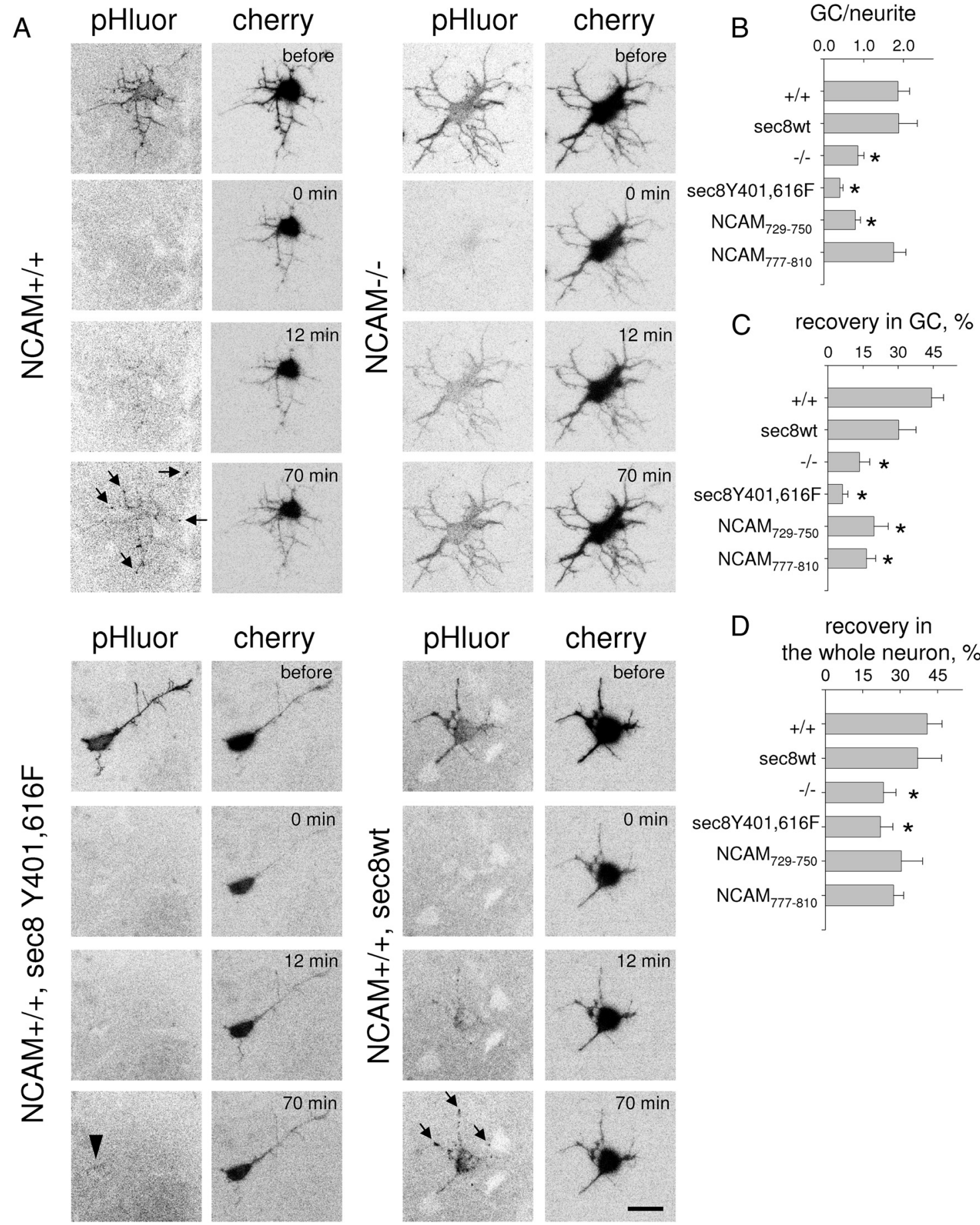

\section{D recovery in} the whole neuron, \%

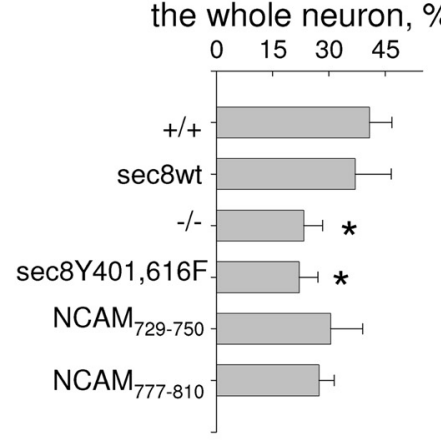

Figure 9. NCAM promotes compartmentalized exocytosis in developing neurons. $A$, Time-lapse recordings of NCAM $+/+$ and NCAM $-/-$ cultured hippocampal neurons cotransfected with synaptobrevin-pHluorin, cherry, and sec 8 constructs. Inverted pHluorin fluorescence signals are shown. Neurons were photobleached ( 0 min). Note pHluorin fluorescence patches (arrows) appearing (12 $\mathrm{min}$ and $70 \mathrm{~min}$ ) in growth cones and along neurites in NCAM + I+ neurons and NCAM $+/+$ neurons cotransfected with sec 8 wt. Diffuse recovery of pHluorin fluorescence is seen in NCAM $-/-$ neurons. pHluorin fluorescence recovery is inhibited in NCAM + / neurons transfected with sec8Y401,616F (arrowhead shows weak diffuse recovery in soma). Scale bar, $20 \mu \mathrm{m}$. High-resolution videos of these recordings are also given as supplemental Videos $\$ 1-S 4$ (available at www.jneurosci.org as supplemental material). $\boldsymbol{B}-\boldsymbol{D}$, Graphs show ratio of pHluorin fluorescence in growth cones $(\mathrm{GC})$ to adjacent segments of neurites $(\boldsymbol{B})$, and recovery of pHluorin fluorescence in growth cones $(\boldsymbol{C})$ and the whole neuron $(\boldsymbol{D})$ at the end of recordings as compared to the levels before photobleaching (mean + SEM from 12-21 growth cones from 10-14 neurons in each group). ${ }^{*} p<0.05$ ( $t$ test, compared to $+/+$ in $\left.\boldsymbol{B}-\boldsymbol{D}\right)$.

the extracellular matrix, is well poised to regulate the localization and function of the exocyst complex in response to extracellular cues. Based on our ELISA experiments, the affinity of the interaction between NCAM140 and the exocyst complex can be predicted to be in the range of several micromoles, which is probably an underestimation, since the interaction can be further potenti- ated in live cells by phosphorylation of sec8. Affinity of the same order of magnitude had been previously detected for the interaction between exo70 and Rho3 (Hamburger et al., 2006; Wu et al., 2010). Further confirming the physiological relevance of this interaction, NCAM deficiency results in a strongly reduced recruitment of exocyst complex subunits to the growth cone membrane 

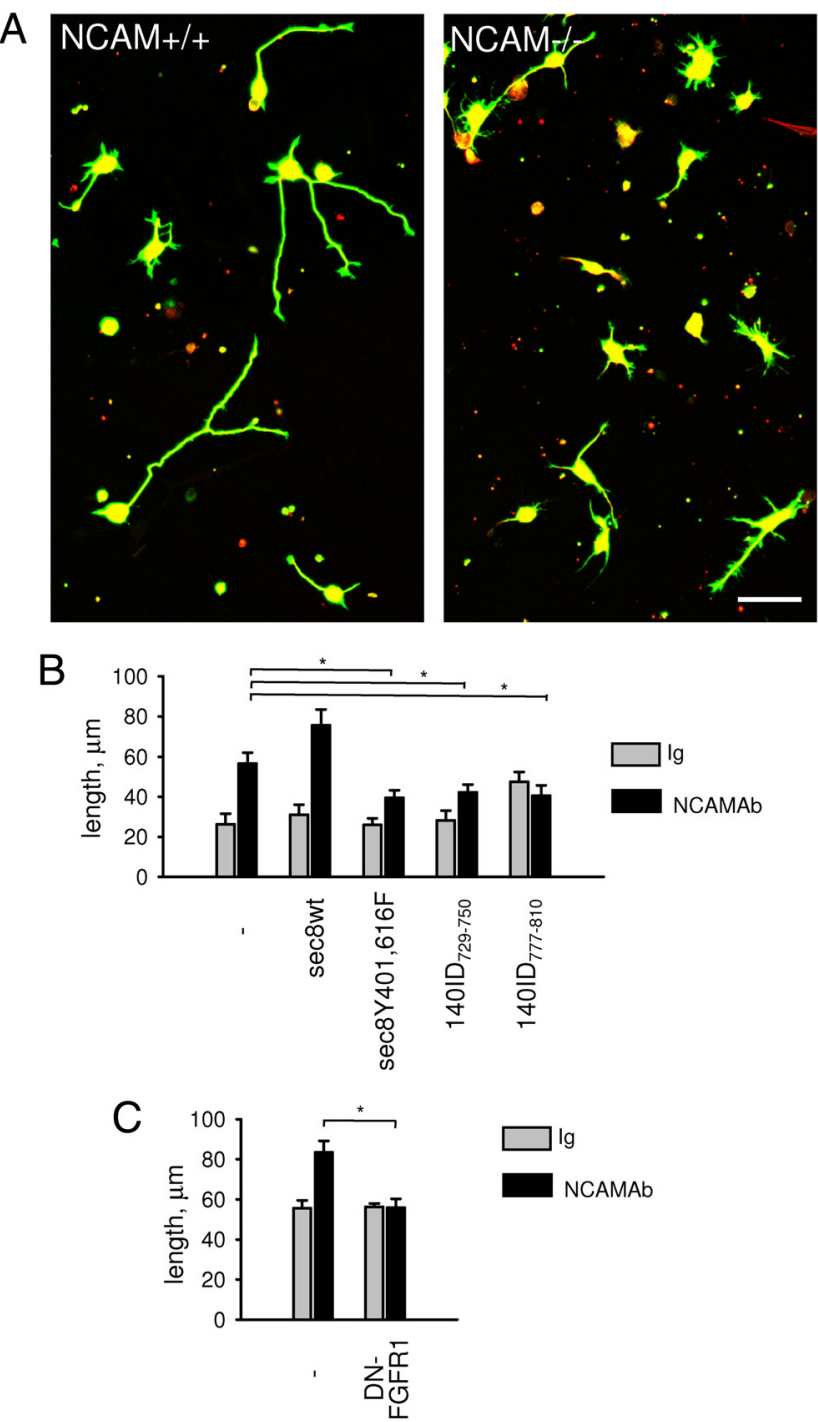

Figure 10. The exocyst complex is required for NCAM-dependent neurite outgrowth. $\boldsymbol{A}$, Cultured NCAM $+/+$ and NCAM $-/$ - hippocampal neurons labeled with antibodies against tau (red) and $\beta$-tubulin (green). Note reduced neurite lengths in NCAM-I- versus $\mathrm{NCAM}+/+$ neurons. Scale bar, $40 \mu \mathrm{m}$. $\boldsymbol{B}, \boldsymbol{C}$, Graph shows total length of all neurites per neuron (mean + SEM, $n \geq 75$ ) in NCAM $+/+$ neurons cotransfected with cherry and the indicated constructs and treated with nonspecific rabbit lgG or NCAM antibodies. ${ }^{*} p<0.05$ ( $t$ test, for $\boldsymbol{B}, \boldsymbol{C}$.

and nontargeted exocytosis along neurites, implicating NCAM as an essential cue that targets the exocyst complex to the sites of exocytosis.

The recruitment of the exocyst complex to membranes is reduced but not blocked in NCAM $-/-$ growth cones or in nontransfected NCAM-negative fibroblasts. This recruitment could be due to the binding of the exocyst complex to lipids (He et al., 2007), suggesting that NCAM plays a regulatory role by potentiating the recruitment and stabilization of the exocyst complex near the surface plasma membrane. It is also conceivable that other cell adhesion molecules localized to growth cones function in parallel with NCAM, thereby allowing growth cones to respond to a variety of extracellular signals. Since E-cadherin expressed by epithelial cells interacts with the exocyst complex and recruits it to the sites of cell-to-cell contacts between these cells (Grindstaff et al., 1998; Yeaman et al., 2004; Nejsum and Nelson, 2007), it is possible that cadherins expressed by neurons also interact with the exocyst complex, but this remains to be investigated.

Even in nonstimulated neurons, disruption of the NCAM/ exocyst complex results in disorganized exocytosis in neuritogenesis, indicating that NCAM functions in the general organization of the exocytotic machinery in neurite outgrowth. Clustering of NCAM, which occurs to a higher extent in growth cones (Fig. 2A) (Leshchyns'ka et al., 2003; Bodrikov et al., 2008) and which promotes sec8 phosphorylation, is likely to play a major role in targeting exocyst-dependent exocytosis preferentially to growth cones. The observation that exocytosis occurs also in a patchy manner along neurites and in somata is in agreement with our previous findings that clusters of NCAM, which are formed along neurites, associate with trans-Golgi derived organelles (Sytnyk et al., 2002). Exocytosis outside of growth cones is, however, probably less efficient in promoting neurite outgrowth since NCAMdeficient neurons show reduced neurite outgrowth albeit strong but disorganized exocytosis all along the neuronal membrane. We propose that exocytosis along neurites is more important for other functions, such as neurite branching or formation of nascent synapses (Sytnyk et al., 2002). The fact that NCAM-/neurons can partially compensate for the defects in exocytosis by upregulating exocytosis at other locations than growth cones, i.e., in somata and neurites, may explain the relatively mild developmental phenotype of NCAM-/- mice. Defects in exocytosis could, however, contribute to the abnormalities in axonal features in the hippocampus of NCAM-/- mice (Cremer et al., 1997; Seki and Rutishauser, 1998).

Our observation that treatment with NCAM antibodies strongly potentiates the interaction between NCAM and the exocyst complex suggests that the extracellular NCAM ligands induce exocytosis of vesicles to expand the surface plasma membrane. It is interesting in this respect that only nonpolysialylated NCAM140 is detectable in the complex with the exocyst complex. Polysialylation of NCAM inhibits its homophilic binding to other NCAM molecules and may therefore interfere with the NCAM/exocyst complex formation.

NCAM-dependent exocytosis depends on the function of the fibroblast growth factor receptor, which plays an essential role in NCAM-dependent neurite outgrowth (Niethammer et al., 2002). Growth cone membrane expansion has also been observed in response to insulin-like growth factor-1, but not brain-derived neurotrophic factor (Pfenninger et al., 2003). Whether these growth factor receptors would also regulate exocyst complex function independently of NCAM and whether the glial cell linederived neurotrophic factor, which signals through NCAM (Paratcha et al., 2003), also induces exocytosis are intriguing questions for future investigations. It is also noteworthy that all NCAM isoforms share the same extracellular domain and can thus bind to the cognate growth factor receptors. It is thus possible that not only NCAM140, which directly binds to the exocyst complex, but also NCAM120 and NCAM180 may indirectly promote neurite outgrowth via influencing FGFR activity.

Inhibition of tyrosine kinase activities strongly reduces the recruitment of the exocyst complex to the plasma membrane, indicating that phosphorylation is critical for exocyst complex function. This view is supported by the observation that the tyrosine-deficient sec8 mutant inhibits compartmentalized exocytosis and NCAM-dependent neurite outgrowth. Another player in NCAM-triggered exocyst function is $\mathrm{Ca}^{2+}$, the influx of which into cells is also essential for NCAM-dependent exocytosis. NCAM induces $\mathrm{Ca}^{2+}$ influx via voltage-dependent $\mathrm{L}$ - and T-type $\mathrm{Ca}^{2+}$ channels (VDCCs) (Schuch et al., 1989; Kiryushko et al., 
2006; Bodrikov et al., 2008). The fact that L-type, but not T-type, VDCCs are required for NCAM-dependent exocytosis in growth cones suggests that $\mathrm{Ca}^{2+}$ influx via different $\mathrm{Ca}^{2+}$ channels may have functionally distinct roles. $\mathrm{Ca}^{2+}$ influx may be required for the SNARE-dependent step in NCAM-dependent vesicle exocytosis, but can also promote the interaction between NCAM and the exocyst complex, which is linked to $\mathrm{Ca}^{2+}$ signaling complexes via the actin cytoskeleton (Shin et al., 2000), which, in turn, is also connected to NCAM via spectrin (Leshchyns'ka et al., 2003). However, the direct interaction between 140ID and exo70 as tested by ELISA was not increased by addition of $\mathrm{Ca}^{2+}$ to the reaction buffer (data not shown). Thus, NCAM not only provides a $\mathrm{Ca}^{2+}$ - independent link for the exocyst complex to the surface plasma membrane, but may also activate a network of molecular interactions accompanying exocyst-dependent exocytosis. In addition, clustering of NCAM induces local proteolysis of the spectrin meshwork (Westphal et al., 2010), the disassembly of which may release sites for new membrane insertions.

As neurons mature, NCAM accumulates at the sites of axodendritic contacts between neurons, playing an important role in contact stabilization and synapse formation (Dityatev et al., 2004; Sytnyk et al., 2006). In concordance with our current findings, we suggest that NCAM also plays a role in regulating the distribution of TGN-derived organelles in neurites of differentiating neurons by promoting compartmentalized accumulation of these organelles at nascent synapses (Sytnyk et al., 2002, 2004). It is interesting in this respect that at the neuromuscular junction, NCAM deficiency results in impaired targeting of synaptic vesicles ( $\mathrm{Ra}$ fuse et al., 2000). Since the exocyst complex has also been described as a cue for defining the sites of assembly of the synaptic machinery (Hazuka et al., 1999), its functional association with NCAM is likely to be important not only for neurite outgrowth, but also for synaptic efficacy by targeting synaptic proteins to active synapses (Sans et al., 2003; Gerges et al., 2006). Whether the functional interaction between NCAM and the exocyst complex is also involved in NCAM- and exocyst-mediated synapse formation and maturation is an important topic for future studies.

\section{References}

Aonurm-Helm A, Berezin V, Bock E, Zharkovsky A (2010) NCAMmimetic, FGL peptide, restores disrupted fibroblast growth factor receptor (FGFR) phosphorylation and FGFR mediated signaling in neural cell adhesion molecule (NCAM)-deficient mice. Brain Res 1309:1-8.

Bodrikov V, Leshchyns'ka I, Sytnyk V, Overvoorde J, den Hertog J, Schachner M (2005) RPTPalpha is essential for NCAM-mediated p59fyn activation and neurite elongation. J Cell Biol 168:127-139.

Bodrikov V, Sytnyk V, Leshchyns'ka I, den Hertog J, Schachner M (2008) NCAM induces CaMKIIalpha-mediated RPTPalpha phosphorylation to enhance its catalytic activity and neurite outgrowth. J Cell Biol 182:1185-1200.

Brennaman LH, Maness PF (2008) Developmental regulation of GABAergic interneuron branching and synaptic development in the prefrontal cortex by soluble neural cell adhesion molecule. Mol Cell Neurosci 37:781-793.

Cotton L, Gibbs GM, Sanchez-Partida LG, Morrison JR, de Kretser DM, O'Bryan MK (2006) FGFR-1 [corrected] signaling is involved in spermiogenesis and sperm capacitation. J Cell Sci 119:75-84.

Cremer H, Lange R, Christoph A, Plomann M, Vopper G, Roes J, Brown R, Baldwin S, Kraemer P, Scheff S, Barthels D, Rajewsky K, Wille W (1994) Inactivation of the N-CAM gene in mice results in size reduction of the olfactory bulb and deficits in spatial learning. Nature 367:455-459.

Cremer H, Chazal G, Goridis C, Represa A (1997) NCAM is essential for axonal growth and fasciculation in the hippocampus. Mol Cell Neurosci 8:323-335.

Cubelos B, Giménez C, Zafra F (2005) The glycine transporter GLYT1 in- teracts with Sec3, a component of the exocyst complex. Neuropharmacology 49:935-944.

Cunningham BA, Hemperly JJ, Murray BA, Prediger EA, Brackenbury R, Edelman GM (1987) Neural cell adhesion molecule: structure, immunoglobulin-like domains, cell surface modulation, and alternative RNA splicing. Science 236:799-806.

Dityatev A, Dityateva G, Sytnyk V, Delling M, Toni N, Nikonenko I, Muller D, Schachner M (2004) Polysialylated neural cell adhesion molecule promotes remodeling and formation of hippocampal synapses. J Neurosci 24:9372-9382.

Gennarini G, Hirn M, Deagostini-Bazin H, Goridis C (1984) Studies on the transmembrane disposition of the neural cell adhesion molecule N-CAM. The use of liposome-inserted radioiodinated N-CAM to study its transbilayer orientation. Eur J Biochem 142:65-73.

Gerges NZ, Backos DS, Rupasinghe CN, Spaller MR, Esteban JA (2006) Dual role of the exocyst in AMPA receptor targeting and insertion into the postsynaptic membrane. EMBO J 25:1623-1634.

Grindstaff KK, Yeaman C, Anandasabapathy N, Hsu SC, Rodriguez-Boulan E, Scheller RH, Nelson WJ (1998) Sec6/8 complex is recruited to cell-cell contacts and specifies transport vesicle delivery to the basal-lateral membrane in epithelial cells. Cell 93:731-740.

Guan KL, Dixon JE (1991) Eukaryotic proteins expressed in Escherichia coli: an improved thrombin cleavage and purification procedure of fusion proteins with glutathione S-transferase. Anal Biochem 192:262-267.

Hamburger ZA, Hamburger AE, West AP Jr, Weis WI (2006) Crystal structure of the S. cerevisiae exocyst component Exo70p. J Mol Biol 356:9-21.

Hazuka CD, Foletti DL, Hsu SC, Kee Y, Hopf FW, Scheller RH (1999) The sec6/8 complex is located at neurite outgrowth and axonal synapseassembly domains. J Neurosci 19:1324-1334.

He B, Xi F, Zhang X, Zhang J, Guo W (2007) Exo70 interacts with phospholipids and mediates the targeting of the exocyst to the plasma membrane. EMBO J 26:4053-4065.

Hoffman S, Sorkin BC, White PC, Brackenbury R, Mailhammer R, Rutishauser U, Cunningham BA, Edelman GM (1982) Chemical characterization of a neural cell adhesion molecule purified from embryonic brain membranes. J Biol Chem 257:7720-7729.

Hsu SC, TerBush D, Abraham M, Guo W (2004) The exocyst complex in polarized exocytosis. Int Rev Cytol 233:243-265.

Kiryushko D, Berezin V, Bock E (2004) Regulators of neurite outgrowth: role of cell adhesion molecules. Ann N Y Acad Sci 1014:140-154.

Kiryushko D, Korshunova I, Berezin V, Bock E (2006) Neural cell adhesion molecule induces intracellular signaling via multiple mechanisms of Ca2+ homeostasis. Mol Biol Cell 17:2278-2286.

Kiselyov VV, Skladchikova G, Hinsby AM, Jensen PH, Kulahin N, Soroka V, Pedersen N, Tsetlin V, Poulsen FM, Berezin V, Bock E (2003) Structural basis for a direct interaction between FGFR1 and NCAM and evidence for a regulatory role of ATP. Structure 11:691-701.

Lebakken CS, Kang HC, Vogel KW (2007) A fluorescence lifetime based binding assay to characterize kinase inhibitors. J Biomol Screen 12:828-841.

Leshchyns'ka I, Sytnyk V, Morrow JS, Schachner M (2003) Neural cell adhesion molecule (NCAM) association with PKCbeta2 via betaI spectrin is implicated in NCAM-mediated neurite outgrowth. J Cell Biol 161:625-639.

Macia E, Ehrlich M, Massol R, Boucrot E, Brunner C, Kirchhausen T (2006) Dynasore, a cell-permeable inhibitor of dynamin. Dev Cell 10:839-850.

Maness PF, Schachner M (2007) Neural recognition molecules of the immunoglobulin superfamily: signaling transducers of axon guidance and neuronal migration. Nat Neurosci 10:19-26.

Matern HT, Yeaman C, Nelson WJ, Scheller RH (2001) The Sec6/8 complex in mammalian cells: characterization of mammalian Sec3, subunit interactions, and expression of subunits in polarized cells. Proc Natl Acad Sci U S A 98:9648-9653.

Miesenböck G, De Angelis DA, Rothman JE (1998) Visualizing secretion and synaptic transmission with $\mathrm{pH}$-sensitive green fluorescent proteins. Nature 394:192-195.

Mohammadi M, Honegger AM, Rotin D, Fischer R, Bellot F, Li W, Dionne CA, Jaye M, Rubinstein M, Schlessinger J (1991) A tyrosine-phosphorylated carboxy-terminal peptide of the fibroblast growth factor receptor (Flg) is a binding site for the SH2 domain of phospholipase C-gamma 1. Mol Cell Biol 11:5068-5078.

Murthy M, Garza D, Scheller RH, Schwarz TL (2003) Mutations in the exo- 
cyst component Sec5 disrupt neuronal membrane traffic, but neurotransmitter release persists. Neuron 37:433-447.

Nejsum LN, Nelson WJ (2007) A molecular mechanism directly linking E-cadherin adhesion to initiation of epithelial cell surface polarity. J Cell Biol 178:323-335.

Niethammer P, Delling M, Sytnyk V, Dityatev A, Fukami K, Schachner M (2002) Cosignaling of NCAM via lipid rafts and the FGF receptor is required for neuritogenesis. J Cell Biol 157:521-532.

Novick P, Medkova M, Dong G, Hutagalung A, Reinisch K, Grosshans B (2006) Interactions between Rabs, tethers, SNAREs and their regulators in exocytosis. Biochem Soc Trans 34:683-686.

Paratcha G, Ledda F, Ibáñez CF (2003) The neural cell adhesion molecule NCAM is an alternative signaling receptor for GDNF family ligands. Cell 113:867-879.

Pfenninger KH, Ellis L, Johnson MP, Friedman LB, Somlo S (1983) Nerve growth cones isolated from fetal rat brain: subcellular fractionation and characterization. Cell 35:573-584.

Pfenninger KH, Laurino L, Peretti D, Wang X, Rosso S, Morfini G, Cáceres A, Quiroga S (2003) Regulation of membrane expansion at the nerve growth cone. J Cell Sci 116:1209-1217.

Rafuse VF, Polo-Parada L, Landmesser LT (2000) Structural and functional alterations of neuromuscular junctions in NCAM-deficient mice. J Neurosci 20:6529-6539.

Riefler GM, Balasingam G, Lucas KG, Wang S, Hsu SC, Firestein BL (2003) Exocyst complex subunit sec8 binds to postsynaptic density protein-95 (PSD-95): a novel interaction regulated by cypin (cytosolic PSD-95 interactor). Biochem J 373:49-55.

Rolf B, Lang D, Hillenbrand R, Richter M, Schachner M, Bartsch U (2003) Altered expression of CHL1 by glial cells in response to optic nerve injury and intravitreal application of fibroblast growth factor-2. J Neurosci Res 71:835-843

Rothbard JB, Brackenbury R, Cunningham BA, Edelman GM (1982) Differences in the carbohydrate structures of neural cell-adhesion molecules from adult and embryonic chicken brains. J Biol Chem 257:11064-11069.

Sans N, Prybylowski K, Petralia RS, Chang K, Wang YX, Racca C, Vicini S, Wenthold RJ (2003) NMDA receptor trafficking through an interaction between PDZ proteins and the exocyst complex. Nat Cell Biol 5:520-530.

Santuccione A, Sytnyk V, Leshchyns'ka I, Schachner M (2005) Prion protein recruits its neuronal receptor NCAM to lipid rafts to activate p59fyn and to enhance neurite outgrowth. J Cell Biol 169:341-354.

Schuch U, Lohse MJ, Schachner M (1989) Neural cell adhesion molecules influence second messenger systems. Neuron 3:13-20.
Seki T, Rutishauser U (1998) Removal of polysialic acid-neural cell adhesion molecule induces aberrant mossy fiber innervation and ectopic synaptogenesis in the hippocampus. J Neurosci 18:3757-3766.

Shea TB, Sapirstein VS (1988) Vesicle-mediated delivery of membrane to growth cones during neuritogenesis in embryonic rat primary neuronal cultures. Exp Cell Biol 56:67-73.

Shin DM, Zhao XS, Zeng W, Mozhayeva M, Muallem S (2000) The mammalian Sec6/8 complex interacts with $\mathrm{Ca}(2+)$ signaling complexes and regulates their activity. J Cell Biol 150:1101-1112.

Sytnyk V, Leshchyns'ka I, Delling M, Dityateva G, Dityatev A, Schachner M (2002) Neural cell adhesion molecule promotes accumulation of TGN organelles at sites of neuron-to-neuron contacts. J Cell Biol 159:649-661.

Sytnyk V, Leshchyns'ka I, Dityatev A, Schachner M (2004) Trans-Golgi network delivery of synaptic proteins in synaptogenesis. J Cell Sci 117:381-388.

Sytnyk V, Leshchyns'ka I, Nikonenko AG, Schachner M (2006) NCAM promotes assembly and activity-dependent remodeling of the postsynaptic signaling complex. J Cell Biol 174:1071-1085.

Vega IE, Hsu SC (2001) The exocyst complex associates with microtubules to mediate vesicle targeting and neurite outgrowth. J Neurosci 21:3839-3848.

Walmod PS, Kolkova K, Berezin V, Bock E (2004) Zippers make signals: NCAM-mediated molecular interactions and signal transduction. Neurochem Res 29:2015-2035.

Walsh FS, Doherty P (1997) Neural cell adhesion molecules of the immunoglobulin superfamily: role in axon growth and guidance. Annu Rev Cell Dev Biol 13:425-456.

Westphal D, Sytnyk V, Schachner M, Leshchyns'ka I (2010) Clustering of the neural cell adhesion molecule (NCAM) at the neuronal cell surface induces caspase-8 and -3 dependent changes of the spectrin meshwork required for NCAM-mediated neurite outgrowth. J Biol Chem 285:42046-42057.

Williams EJ, Walsh FS, Doherty P (1994) The production of arachidonic acid can account for calcium channel activation in the second messenger pathway underlying neurite outgrowth stimulated by NCAM, N-cadherin, and L1. J Neurochem 62:1231-1234.

Wu H, Turner C, Gardner J, Temple B, Brennwald P (2010) The Exo70 subunit of the exocyst is an effector for both $\mathrm{Cdc} 42$ and Rho3 function in polarized exocytosis. Mol Biol Cell 21:430-442.

Yeaman C, Grindstaff KK, Nelson WJ (2004) Mechanism of recruiting Sec6/8 (exocyst) complex to the apical junctional complex during polarization of epithelial cells. J Cell Sci 117:559-570.

Zakharenko S, Popov S (1998) Dynamics of axonal microtubules regulate the topology of new membrane insertion into the growing neurites. J Cell Biol 143:1077-1086. 